\title{
Modeling and Combined Application of MOEA/D and TOPSIS to Optimize WEDM Performances of A286 Superalloy
}

Subhankar Saha ( $\nabla$ sahamech90@gmail.com )

National Institute of Technology Silchar https://orcid.org/0000-0003-3049-8084

Saikat Ranjan Maity

National Institute of Technology Silchar

Sudip Dey

National Institute of Technology Silchar

Saykat Dutta

National Institute of Technology Silchar

\section{Research Article}

Keywords: Wire Electric Discharge Machining, modelling, optimization, MOEA/D, TOPSIS

Posted Date: April 28th, 2021

DOI: https://doi.org/10.21203/rs.3.rs-326775/v1

License: (a) (i) This work is licensed under a Creative Commons Attribution 4.0 International License.

Read Full License 


\section{Modeling and combined application of MOEA/D and TOPSIS to optimize WEDM performances of A286 Superalloy}

Subhankar Saha ${ }^{a}$, Saikat Ranjan Maity ${ }^{* a}$, Sudip Dey ${ }^{\mathrm{a}}$, and Saykat Dutta ${ }^{\mathrm{b}}$

${ }^{a}$ Department of Mechanical Engineering, National Institute of Technology Silchar, Silchar, Assam, India.

${ }^{b}$ Department of Mathematics, National Institute of Technology Silchar, Silchar, Assam, India.

Corresponding author: Saikat Ranjan Maity, Mechanical Engineering Department, National

Institute of Technology Silchar, Silchar, Assam, India

Email of the Corresponding author: srmaity@mech.nits.ac.in 


\begin{abstract}
Superalloys are categorized as difficult to process materials with a broad spectrum of applications in industries. Process modeling and optimization of Wire Electric Discharge Machining (WEDM) performances on Nickel and Titanium based superalloys are widely investigated. However, such investigations on Iron-based Superalloy are still lacking and hence probed in the present article. Thus, the first part of the paper targets modelling the correlation between the performance parameters and the control parameters with two popular techniques: response surface methodology (RSM) and artificial neural network (ANN) for WEDM of a typical Iron-based superalloy, i.e., A286 Superalloy. A comparison is carried out between the model estimates and the experimental values to check ANN and RSM's prediction accuracy. The estimates by the ANN model are exact and consistent with the experimental results. An analysis of variance (ANOVA) test is performed to perceive the degree of statistical significance of parameters. Moreover, in the second part, a novel two-stage procedure, i.e., a multiobjective evolutionary algorithm based on decomposition (MOEA/D) in collaboration with a decisionmaking method, i.e., a technique for order preference by similarity to ideal solution (TOPSIS) method is implemented to search the optimal condition for process performances. The optimal parametric combination recommended by the proposed optimization approach is $T_{o n}=130 \mu \mathrm{s}$, $T_{\text {off }}=52 \mu \mathrm{s}, I_{\text {peak }}=12 \mathrm{~A}, W_{f}=5 \mathrm{~m} / \mathrm{min}$ and $S V=30$ volt. The proposed optimization technique can also be exploited in other manufacturing processes.
\end{abstract}

Keywords Wire Electric Discharge Machining, modelling, optimization, MOEA/D, TOPSIS

Nomenclature

WEDM Wire Electric Discharge Machining

$M R R \quad$ Material removal rate

SR Surface Roughness 


\begin{tabular}{|c|c|}
\hline$T_{o n}$ & Pulse on time \\
\hline$T_{o f f}$ & Pulse off time \\
\hline$I_{\text {peak }}$ & Peak current \\
\hline$W_{f}$ & Wire feed rate \\
\hline$S V$ & Servo voltage \\
\hline$C s$ & Cutting speed \\
\hline$L$ & Plate thickness \\
\hline$\lambda_{c}$ & Cut-off length \\
\hline
\end{tabular}

MOEA/D Multiobjective evolutionary algorithm based on decomposition

MOP Multiobjective optimization problem

NSGA 2 Non-dominated Sorting Genetic Algorithm 2

TOPSIS Technique for order preference by similarity to ideal solution (TOPSIS)

$S^{+} \quad$ Positive Ideal solution

$S^{-} \quad$ Negative Ideal solution

$E_{i}^{+} \quad$ Separation from the positive ideal solution

$E_{i}^{-} \quad$ Separation from the negative ideal solution

$C C_{i} \quad$ Relative closeness coefficient

MCDM Multiple-criteria Decision-Making 


$\begin{array}{cl}\text { RSM } & \text { Response Surface Methodology } \\ \text { ANN } & \text { Artificial Neural Network } \\ \text { MLP } & \text { Multi-Layer Perceptron } \\ d_{\max } & \text { The maximum value of the response parameter } \\ d_{\min } & \text { The minimum value of the response parameter } \\ d_{i} & \text { The nominal value of the response parameter } \\ \text { trainlm } & \text { Lavenberg-Marquardt algorithm } \\ \text { learngd } & \text { Gradient Descent Learning Function } \\ \text { PBMOO } & \text { Preference-based Multiobjective Optimization } \\ \text { TLBO } & \text { Teaching-Learning based Optimization }\end{array}$

\section{Introduction}

Superalloys (Nickel, Iron, and Titanium-based alloys) are the most exploited material in sectors like medical, automotive, aerospace, and nuclear reactors on account of their appealing properties at elevated temperatures (Khalid et al. 1999; Pollock et al. 2006). On account of such alloys, machining of superalloys by conventional machining practices frequently pose challenges like the evolution of high cutting forces during machining, the formation of burrs, the shortening of tool life, etc. To evade such challenges, machining such alloys is successfully exploited by advanced machining processes like electrochemical machining, spark erosion machining (EDM, Wire-EDM), laser beam machining, etc. Yet, amongst the advanced machining processes, WireEDM has gained lots of popularity and attention for the last couple of decades as it has more potential and flexibility in generating complex contours due to its embedded technology (Sharma et al. 2015). Moreover, wire-EDM profiles are highly accurate and precise, making the machined 
components eligible for critical applications. Regardless of its application potentials, wire-EDM has its problems because of the process anisotropy, instabilities, and participation of several process variables during the process. Thus, modeling the process is of utmost importance to understand the process behavior. Furthermore, it is equally important to perform the machining at optimal operating conditions to balancethe quality parameter and the productivity parameter.

In consideration of the above, researchers have explored various approaches for modeling and predicting the responses (Majumder et al. 2018; Saha et al. 2017). Furthermore, researchers also adopt different optimization procedures for determining the optimal combination of parameters (Saha et al. 2016; Saha et al. 2013).

Mandal et al. (2016) modeled four performance attributes with the process parameters during WEDM cutting of Nimonic C-263 superalloy. The desirability function determines the optimal operating conditions. In a recent investigation, the ANN model predicted important performance variables of the WEDM process of Inconel 718. Furthermore, the performance variables are optimized concurrently, exploiting a multi-response signal-to-noise (MRSN) ratio in conjunction withthe Taguchi method (Ramakrishnan and Karunamoorthy 2008) . Tonday et al. (2019) performed the Optimization of machining time and surface roughness using RSM in WEDM of Inconel 718. Khan et al. (2014) reported the implementation of grey relational analysis for carrying out the Optimization of surface roughness and microhardness simultaneously during the WEDM process. Tarng et al. (1995) exploited the simple weighting strategy to aggregate the two objectives (cutting velocity and surface roughness) into a single objective and then implemented simulated annealing to identify the optimal parameters.

Similarly, a research group adopted the Tabu-search algorithm to minimize the objective function (derived from the weighted sum of the performance parameters) and then presented the optimal parametric conditions based on preferences (Sadeghi et al. 2011). Another investigation connected with the WEDM of Inconel-690 is mapping the performance parameters with the process parameters by employing RSM. Furthermore, the authors proposed a modified cuckoo search algorithm to determine the optimal responses (Rao et al. 2017). Nayak et al. (2016) proposed an ANN model to establish the relationship between the input parameters and the performance parameters during taper cutting operation of a deep-cryo-treated Inconel 718 in the WEDM process. Furthermore, the bat algorithm is employed to carry out the Optimization. In a 
different attempt, Kuriakose et al. (2005) proposed a Non-dominated Sorted Genetic Algorithm technique to determine the multiple varieties of optimal parameters for two performance parameters (Pareto set) during wire EDM of Ti6Al4V. Similarly, Garg et al. (2012) reported a group of Pareto optimal solutions for the conflicting objectives (CR and SR) in wire-EDM of Ti 6-2-4-2 alloy by exploiting the NSGA-II algorithm.

Based on the literature stated above, most of the initial investigations on modeling and Optimization of Wire EDM performances are carried on Nickel and Titanium-based alloys. Still, sparse literature exists on the WEDM of Iron-based superalloys. Therefore, the present work attempts to model and Optimize WEDM performances for an Iron-based Superalloy, namely A286 Superalloy.This material is considered in the current work as it is categorized as hard-tocut Superalloy, which is extensively used for high-temperature applications (Musavi et al. 2018). Besides, this material is also deployed in frames, after-burner parts, fasteners, casings, rotors, and in other applications due to its attractive mechanical properties and good thermal resistivity (Alphonsa et al. 2015).

Classical optimization methods such as the weighted sum method are implemented in some of the literature to optimize WEDM responses. The weighted sum method is a technique that enables the transformation of multiobjective optimization framework to a single objective optimization framework by suitably assigning weights to different objectives. However, those techniques have their limitations, such as the inability to handle discontinuous functions, having a priori information on the relative preferences of the objectives, problems related to nonconvexity, delivering only one solution, etc (Ngatchou et al. 2005). Thus, multiobjective evolutionary algorithms (MOEAs) such as NSGA-II, etc., have become popular in the WEDM process as they eradicate such limitations and offer a collection of Pareto optimal solutions. Nevertheless, literature almost lacks the implementation of MOEAs based on a different framework, i.e., multiobjective optimization based on decomposition (MOEA/D) in the WEDM process. MOEA/D furnishes well-diversified Pareto optimal solutions for multiobjectives. Besides, the computational burden in MOEA/D is less than other popular algorithms like multiobjective genetic local search (MOGLS) and nondominated sorting genetic algorithm II (NSGA-II). Besides, an additional feature of MOEA/D includes accounting for disparate objectives by simple normalization. It is intended to employ MOEA/D as the optimization 
algorithm in our work on account of such interesting features. Again, it is evident that MOEAs used in WEDM has produced a set of non-dominated solutions (Pareto optimal solutions). The limitation lies in choosing the best optimal solution amongst the non-dominated optimal group, which creates ambiguity among decision-makers. Thus, a suitable decision-making strategy, i.e., a technique for order preference by similarity to ideal solution (TOPSIS), is adopted in this paper to account for such ambiguity and therefore aids in identifying the best optimal point.

Because of the discussions mentioned above, the following objectives are planned for the present work. The overall workflow to achieve the objectives is demonstrated in Fig. 1.

(1) To model the performance parameters (MRR and SR) with RSM and ANN input parameters. Furthermore, the two techniques are juxtaposed with the experimental observations to check the two models' prediction accuracy.

(2) A novel two-stage optimization procedure, i.e., MOEA/D in conjunction with TOPSIS, is employed for selecting an optimal condition for the WEDM responses.

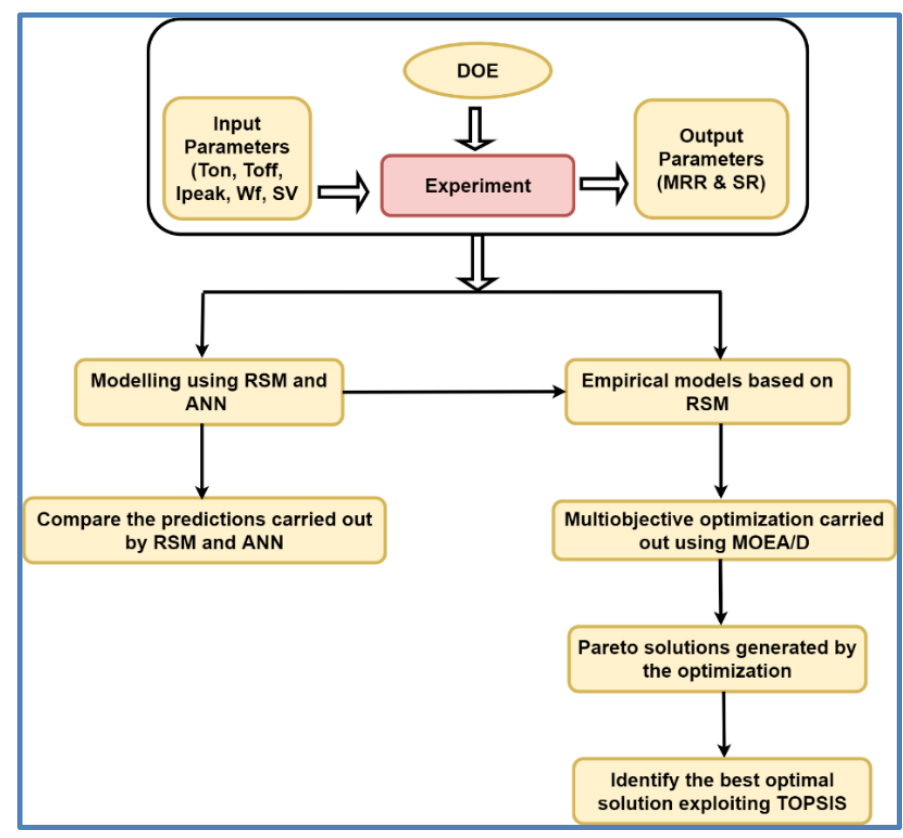

Fig. 1 Work-flow of the present study. 


\section{Materials and Experimental Details}

\subsection{Material Composition}

In the current investigation, the material is an A286 alloy. The composition of this alloy is: C (0.05 wt. \%), Mn (2 wt. \%), S (0.025 wt. \%), Al (0.35 wt. \%), Cr (14 wt. \%), Ni (25 wt. \%), V (0.2 wt. \%), Si (1wt \%), Mo (1.21 wt. \%), Ti (2.1 wt. \%) and Fe (balance).

\subsection{Experimental Details}

The machining runs have been performed on the Ultra cut F-1 model of Wire EDM machine tool. A view of the WEDM machining setupis displayed in Fig.2. The longitudinal (Yaxis) and lateral (X-axis) travel ranges are 300 and $400 \mathrm{~mm}$, respectively, and the $\mathrm{z}$-direction travel range is $250 \mathrm{~mm}$. The maximum workpiece size that can be mounted on the machine is $(600 \times 780 \times 250) \mathrm{mm}$. The workpieceused for this study is of dimension $(200 \times 150 \times 5) \mathrm{mm}$, and the geometry proposed for the WEDM cut is a square of size $(12 \mathrm{~mm} \times 12 \mathrm{~mm})$. Brass wire overlaid with a zinc layer $(250 \mu \mathrm{m}$ diameter) is deployed as the tool as it provides better flushing conditions in the spark gap (Dauw and Albert 1992). The dielectric fluid used in this study is deionized water.

In this research, the five process parameters, namely pulse on time $\left(T_{o n}\right)$, peak current $\left(I_{\text {peak }}\right)$, pulse off time $\left(T_{o f f}\right)$, servo voltage $(S V)$, and wire feed rate $\left(W_{f}\right)$ are controlled based on earlier works. Three levels for each parameter are considered based on preliminary experiments. During the selection, the bounds of the process parameters indicate fewer chances of wire breakage. The parameters to be controlled and their respective levels are furnished in tabular form, as shown in Table 1.

Table 1 Control parameters and their levels

\begin{tabular}{cccc}
\hline Parameters & \multicolumn{3}{c}{ Levels } \\
\cline { 2 - 4 } & 1 & 2 & 3 \\
\cline { 2 - 4 }$T_{\text {on }}(\mu \mathrm{s})$ & 120 & 125 & 130 \\
$T_{\text {off }}(\mu \mathrm{s})$ & 48 & 52 & 56 \\
$I_{\text {peak }}(\mathrm{A})$ & 10 & 11 & 12 \\
$W_{f}(\mathrm{~m} / \mathrm{min})$ & 5 & 7 & 9
\end{tabular}




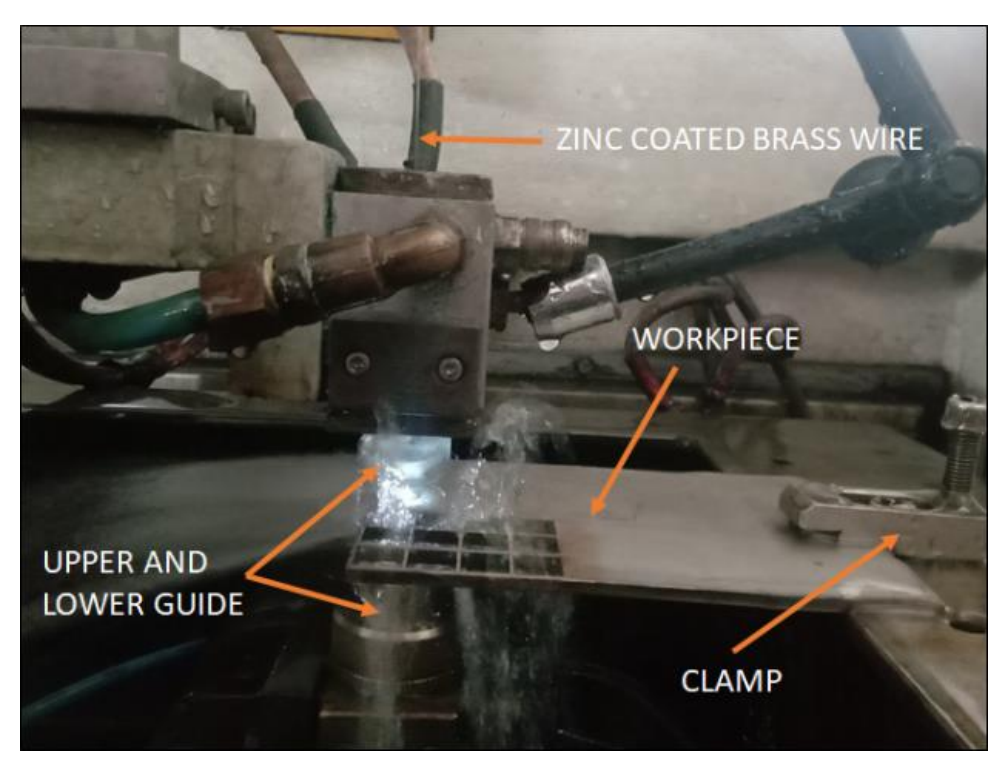

Fig. 2 WEDM machining setup.

The experimental layout is designed based on the $\mathrm{L}_{27}$ orthogonal array because Taguchi's $\mathrm{L}_{27}$ orthogonal array intends to exploit only 27 different combinations of parameter levels to extract similar information by conducting $243\left(3^{5}\right)$ experiments. Thus, 27 experiments run with each experiment replicated thrice for assessing the averaged values of responses such as MRR and SR. Table 2 portrays the different process parametric conditions along with the experimental outcomes.

Table 2 Experimental datasets

\begin{tabular}{cccccccc}
\hline $\begin{array}{c}\text { Machining } \\
\text { trials }\end{array}$ & $\mathrm{T}_{\text {on }}$ & $\mathrm{T}_{\text {off }}$ & $\mathrm{I}_{\text {peak }}$ & $\mathrm{W}_{\mathrm{f}}$ & $\mathrm{SV}$ & $\begin{array}{c}\mathrm{MRR} \\
\left(\mathrm{mm}^{2} / \mathrm{min}\right)\end{array}$ & $\begin{array}{c}\mathrm{SR} \\
(\mu \mathrm{m})\end{array}$ \\
\hline 1. & 120 & 48 & 10 & 5 & 30 & 2.45 & 0.83 \\
2. & 120 & 48 & 11 & 7 & 35 & 18.90 & 3.50 \\
3. & 120 & 48 & 12 & 9 & 40 & 15.65 & 3.13 \\
4. & 120 & 52 & 10 & 7 & 35 & 1.70 & 0.80 \\
5. & 120 & 52 & 11 & 9 & 40 & 12.85 & 2.80
\end{tabular}




\begin{tabular}{llllllll} 
6. & 120 & 52 & 12 & 5 & 30 & 15.35 & 2.43 \\
7. & 120 & 56 & 10 & 9 & 40 & 1.15 & 0.77 \\
8. & 120 & 56 & 11 & 5 & 30 & 13.85 & 2.87 \\
9. & 120 & 56 & 12 & 7 & 35 & 11.30 & 2.90 \\
10. & 125 & 48 & 10 & 7 & 40 & 2.10 & 1.07 \\
11. & 125 & 48 & 11 & 9 & 30 & 22.95 & 3.53 \\
12. & 125 & 48 & 12 & 5 & 35 & 23.15 & 3.77 \\
13. & 125 & 52 & 10 & 9 & 30 & 1.75 & 1.02 \\
14. & 125 & 52 & 11 & 5 & 35 & 22.10 & 3.20 \\
15. & 125 & 52 & 12 & 7 & 40 & 17.70 & 3.37 \\
16. & 125 & 56 & 10 & 5 & 35 & 1.70 & 0.93 \\
17. & 125 & 56 & 11 & 7 & 40 & 15.15 & 3.10 \\
18. & 125 & 56 & 12 & 9 & 30 & 15.75 & 3.30 \\
19. & 130 & 48 & 10 & 9 & 35 & 2.45 & 1.17 \\
20. & 130 & 48 & 11 & 5 & 40 & 27.00 & 3.80 \\
21. & 130 & 48 & 12 & 7 & 30 & 37.10 & 3.87 \\
22. & 130 & 52 & 10 & 5 & 40 & 2.10 & 1.13 \\
23. & 130 & 52 & 11 & 7 & 30 & 25.25 & 3.90 \\
24. & 130 & 52 & 12 & 9 & 35 & 27.60 & 3.33 \\
25. & 130 & 56 & 10 & 7 & 30 & 1.75 & 0.97 \\
26. & 130 & 56 & 11 & 9 & 35 & 20.90 & 3.77 \\
27. & 130 & 56 & 12 & 5 & 40 & 29.70 & 3.37 \\
\hline
\end{tabular}

During the measurement of MRR, the kerf width is eliminated as the variation in kerf width is assumed to have a negligible impact on MRR as compared to the variation in the cutting speed and thickness of the workpiece. Therefore, MRR is evaluated by the following Eq. (1). Similar assumptions and methodology are seen in some of the previous works (Ramakrishnan and Karunamooorthy et al. 2006; Chalisgaonkar et al. 2015).

$$
\operatorname{MRR}\left(\mathrm{mm}^{2} / \mathrm{min}\right)=\text { Cutting speed }(C s) \times \text { plate thickness }(L)
$$


SR is calculated by measuring the arithmetic mean roughness ( $\mathrm{Ra}$ ) of the machined surface using Surtronic S-128 S-Series roughness tester. The measurement of Ra is carried out by traversing the probe along a length of $10 \mathrm{~mm}$ (cut-off length $\left(\lambda_{c}\right)=0.8 \mathrm{~mm}$ ) in a direction perpendicular to the wire movement direction. For each SR evaluation, Ra is measured thrice from three different positions and averaged out.

\section{Optimisation Approach}

It is often viewed in the WEDM process that when the MRR is high, the surface roughness also increases due to the process's inherent nature. Nonetheless, stringent industrial requirements seek to yield high MRR and low SR to augment productivity and product quality, respectively. Thus, the contemporary problem is a multiobjective optimization problem (MOP) wherein the targets maximizes the MRR and minimizes the SR simultaneously subjected to a list of parameter bounds. The MOP is stated as below:

Maximize MRR ( $\left.T_{o n}, \mathrm{~T}_{\mathrm{off}}, I_{p e a k}, W_{f}, S V\right)$

Minimize SR ( $\left.T_{o n}, T_{o f f}, I_{p e a k}, W_{f}, S V\right)$

$$
\begin{array}{ll} 
& 120 \leq T_{\text {on }} \leq 130 \\
& 48 \leq T_{\text {off }} \leq 56 \\
\text { Subjected to: } & 10 \leq I_{\text {peak }} \leq 12 \\
& 5 \leq W_{f} \leq 9 \\
& 30 \leq S V \leq 40
\end{array}
$$

We propose a metaheuristic optimization technique to address the aforementioned problem, herein a metaheuristic optimization technique i.e., multiobjective evolutionary algorithm based on decomposition (MOEA/D) for solving the MOP. A large number of optimal solutions (non-dominated solutions) MOEAs of any kind generate a large number of optimal solutions (non-dominated solutions). But owing to practical constraints and to avoid overflow of information, it is prudent to stick to a single solution that can meet both the targets to some extent. However,the solutions subjective ranking can be a choice but, it is complicated and imprecise. Thus, we adopted a comprehensive approach to rank the non-dominated solution by exploiting the TOPSIS method in this work.

\subsection{MOEA/D optimization}


MOEA/D, an evolutionary-based multiobjective optimization technique that fundamentally disintegrates a multiobjective optimization problem (MOP)into scalar subproblems, which are thereafter optimized concurrently (Zhang et al. 2007). Optimization of any subproblem is carried out only by exploiting information from its nearest subproblems. Meanwhile, the population of solutions is evolved using an evolutionary algorithm. Distances of nearest sub-problems are between the weight vectors. Decomposition in MOEA/D ventured by three approaches is the weighted sum approach, Tchebycheff approach, and penalty-based boundary interaction (PBI) approach (Wang et al. 2015). The flow diagram of the MOEA/D algorithm is provided below (see Fig. 3):

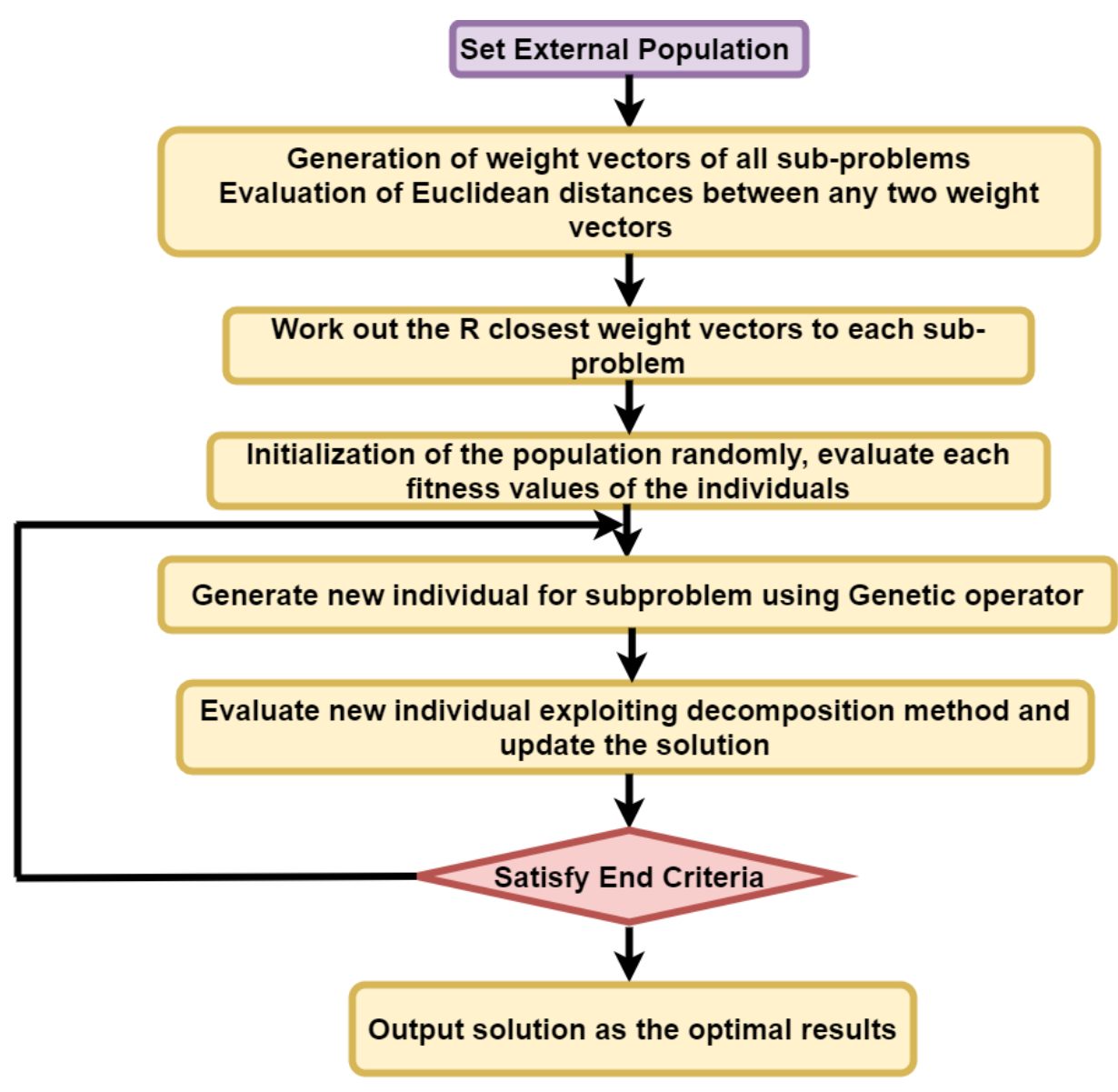

Fig. 3 MOEA/D flow diagram. 


\subsection{Identification of the best optimal solution by TOPSIS}

TOPSIS, a competent MCDM technique initiated by Hwang et al. (1981) is employed to endorse the best alternative solution from a collection of Pareto optimal solutions. The underlying concept is that if any solution is at the shortest geometric distance from a positive ideal solution and simultaneously be at the longest geometric distance from a negative ideal solution, then the solution is said to be the best compromise solution. The computational steps of TOPSIS are presented below:

Step 1 Frame the normalized decision matrix, each element $r_{i j}$ is evaluated by:

$$
r_{u v}=\frac{x_{u v}}{\sqrt{\sum_{u=1}^{m} x_{u v}^{2}}}
$$

Where $x_{u v}=$ response of $u^{\text {th }}$ alternative with respect to $v^{\text {th }}$ criterion.

Step 2 Calculate the weighted normalized decision matrix, the elements are specified by $n_{u v}$

$$
n_{u v}=w_{v} * r_{u v} u=1,2, \ldots m, v=1,2
$$

Step 3 Determine the positive ideal solution $S^{+}$and the negative ideal solution $S^{-}$

$$
\begin{aligned}
& S^{+}=\left(\max \left[n_{11}, \ldots . n_{m 1}\right], \min \left[n_{12}, \ldots . n_{m 2}\right]\right) \\
& S^{-}=\left(\min \left[n_{11}, \ldots . n_{m 1}\right], \max \left[n_{12}, \ldots . n_{m 2}\right]\right)
\end{aligned}
$$

Step 4 Compute the separation from the positive ideal solution, $E_{i}^{+}$and the separation from the negative ideal solution, $E_{i}^{-}$based on n-dimensional Euclidean distance.

$$
\begin{gathered}
E_{u}^{+}=\sqrt{\sum_{v=1}^{2}\left(v_{u v}-s_{v}^{+}\right)^{2}} u=1,2,3, \ldots m v=1,2 \\
E_{u}^{-}=\sqrt{\sum_{j=1}^{2}\left(v_{i j}-s_{j}^{-}\right)^{2}} u=1,2,3, \ldots m v=1,2
\end{gathered}
$$

Step 5 Compute the relative closeness $\left(C C_{u}\right)$ to the ideal solution as given below: 
$C C_{u}=\frac{E_{u}^{-}}{E_{u}^{+}+E_{u}^{-}}, \quad u=1,2,3, \ldots m$

\section{Modelling using RSM}

Response Surface Methodology (RSM) is entirely a statistically based tool for developing, improving, and optimization processes. This includes three steps which are (a) design an experimental layout to explore the domain of the process or predictor variables (b) build an empirical model that maps the responses with the predictor variables (c) optimization of the process response. A first-order or a second-order polynomial is used to build an empirical model. The following equation gives the first-order model:

$$
\eta=\underset{\text { Intercept }}{\beta_{0}}+\beta_{1} x_{4}+\underset{\text { MainEffects }}{\beta_{2}} x_{24}+\beta_{23} x_{3}+\beta_{124} x_{1} x_{2} \frac{4}{4} \underset{\text { Interactions }}{\beta_{13}} x_{1} x_{3}+\beta_{23} x_{23} x_{3}+\ldots
$$

This is the first-order model inclusive of main effects and interactions. Interaction terms are incorporated to capture the curvature if present on the response surface. However, in many instances, the curvature in the actual response surface is so prominent that the first-order model is found to be inadequate. In such cases, a second-order model becomes an appropriate alternative. The second-order model is displayed in the following equation:

$\eta=\beta_{0}+\beta_{1} x_{1}+\beta_{2} x_{2}+\beta_{3} x_{3}+\beta_{11} x_{1}^{2}+\beta_{22} x_{2}^{2}+\beta_{3} x_{3}^{2}+\beta_{12} x_{1} x_{2}+\beta_{13} x_{1} x_{3}+\beta_{23} x_{2} x_{3}+\ldots$

In the present investigation, having acquainted with the complexity of the machining

process. full second-order quadratic models are considered to frame the objective functions for predictions as well as forOptimization. The empirical models are displayed below:

$$
\begin{aligned}
& M R R=567-20.39 T_{\text {on }}-2.91 T_{\text {off }}+102.8 I_{\text {peak }}+28.4 W_{f}+2.83 S V+0.0497 T_{\text {on }}{ }^{2}+0.0354 T_{\text {off }}{ }^{2} \\
& -8.192 I_{\text {peak }}^{2}-0.037 W_{f}^{2}-0.0302 S V^{2}+0.0117 T_{\text {on }} * T_{\text {off }}+0.858 T_{\text {on }} * I_{\text {peak }}-0.1511 T_{\text {on }} * W_{f} \\
& -0.0034 T_{\text {on }} * S V-0.244 T_{\text {off }} * I_{\text {peak }}-0.1140 T_{\text {off }} * W_{f}+0.0196 T_{\text {off }} * S V-0.326 I_{\text {peak }} * W_{f} \\
& -0.145 I_{\text {peak }} * S V \\
& S R=-177.3+0.59 \text { Ton }-0.889 \text { Toff }+27.26 \text { Ipeak }+1.82 W f+0.110 S V-0.00276 \text { Ton }^{2}+0.00934 \text { Toff }^{2} \\
& -1.2656 \text { Ipeak }^{2}-0.0323 \mathrm{Wf}^{2}-0.00642 S V^{2}+0.00014 \text { Ton } * \text { Toff }+0.0177 \text { Ton } * \text { Ipeak }-0.0157 \text { Ton } * W f \\
& -0.0034 \text { Ton } * S V-0.244 \text { Toff } * \text { Ipeak }-0.1140 \text { Toff } * W f+0.0196 \text { Toff } * S V-0.326 \text { Ipeak } * W f \\
& -0.145 \text { Ipeak } * S V
\end{aligned}
$$


In addition, an ANOVA test is carried out on statistical software (MINITAB 17 version) to analyze the significant parameters (individual and interacting parameters) affecting the two response parameters, i.e., $M R R$ and $S R$ (see Table 3 and Table 4). The models (Eq. $11 \&$ Eq. 12) are found to fit the experimental data adequately for a confidence level of 95\% (user-defined criteria) since from the ANOVA analysis (Table $3 \&$ Table 4) for both the models (MRR and $S R$ ), P-values obtained are less than 0.05 . To assess the statistical significance of individual parameters and the statistical significance of interacting parameters on performance parameters, we observe the values of two parameters, i.e., F-value and P-value. Any statistically significant parameter is likely to have a higher F-value (more than 1) and a lower P-value (less than 0.05).

Table 3 ANOVA analysis for MRR

\begin{tabular}{cccccc}
\hline & & & & & \\
Source & DF & Adj SS & Adj MS & F-Value & P-Value \\
\hline Regression & 19 & 2886.14 & 151.902 & 53.62 & 0.000 \\
$T_{\text {on }}$ & 1 & 21.96 & 21.956 & 7.75 & 0.027 \\
$T_{\text {off }}$ & 1 & 0.64 & 0.641 & 0.23 & 0.649 \\
$I_{\text {peak }}$ & 1 & 56.36 & 56.361 & 19.90 & 0.003 \\
$W_{f}$ & 1 & 15.58 & 15.581 & 5.50 & 0.051 \\
$S V$ & 1 & 0.69 & 0.690 & 0.24 & 0.637 \\
$T_{\text {on }} * T_{\text {on }}$ & 1 & 9.25 & 9.250 & 3.27 & 0.114 \\
$T_{\text {off }} * T_{\text {off }}$ & 1 & 1.93 & 1.927 & 0.68 & 0.437 \\
$I_{\text {peak }} * I_{\text {peak }}$ & 1 & 402.62 & 402.620 & 142.12 & 0.000 \\
$W_{f}^{*} W_{f}$ & 1 & 0.08 & 0.084 & 0.03 & 0.868 \\
$S V^{*} S V$ & 1 & 2.57 & 2.569 & 0.91 & 0.373 \\
$T_{\text {on }} * T_{\text {off }}$ & 1 & 0.43 & 0.431 & 0.15 & 0.708 \\
$T_{\text {on }} * I_{\text {peak }}$ & 1 & 145.79 & 145.788 & 51.46 & 0.000 \\
$T_{\text {on }} * W_{f}$ & 1 & 10.28 & 10.276 & 3.63 & 0.099 \\
$T_{\text {on }} * S V$ & 1 & 0.02 & 0.019 & 0.01 & 0.937 \\
$T_{\text {off }} * I_{\text {peak }}$ & 1 & 5.70 & 5.704 & 2.01 & 0.199 \\
$T_{\text {off }} * W_{f}$ & 1 & 8.23 & 8.232 & 2.91 & 0.132 \\
$T_{\text {off }} * S V$ & 1 & 1.22 & 1.216 & 0.43 & 0.533 \\
$I_{\text {peak }} * W_{f}$ & 1 & 4.21 & 4.209 & 1.49 & 0.262 \\
$I_{\text {peak }} * S V$ & 1 & 4.15 & 4.148 & 1.46 & 0.266 \\
Error & 7 & 19.83 & 2.833 & & \\
$T_{\text {otal }}$ & 26 & 2905.97 & & & \\
\hline & & & &
\end{tabular}

From the ANOVA analysis for $M R R$ (Table 3), it is evident that $T_{o n}, T_{o f f}$, and $W f$ are influential parameters affecting the MRR. Apart from that, $\left(T_{o n} * I_{p e a k}\right)$ and $\left(T_{o n} * W f\right)$ is the 
momentous two-way interaction parameters affecting the $M R R$. In the same manner, it can be depicted from the ANOVA analysis for $S R$ (Table 4) that $I_{\text {peak }}$ is the only influential parameter affecting the surface roughness, and there are no two-way interaction parameters that affect the SR.

Table 4 ANOVA analysis for SR

\begin{tabular}{cccccc}
\hline & & & & & \\
Source & DF & Adj SS & Adj MS & F-Value & P-Value \\
\hline Regression & 19 & 36.2142 & 1.90601 & 34.01 & 0.000 \\
$T_{\text {on }}$ & 1 & 0.0184 & 0.01839 & 0.33 & 0.585 \\
$T_{\text {off }}$ & 1 & 0.0598 & 0.05983 & 1.07 & 0.336 \\
$I_{\text {peak }}$ & 1 & 3.9644 & 3.96442 & 70.75 & 0.000 \\
$W_{f}$ & 1 & 0.0636 & 0.06357 & 1.13 & 0.322 \\
$S V$ & 1 & 0.0010 & 0.00105 & 0.02 & 0.895 \\
$T_{\text {on }} * T_{\text {on }}$ & 1 & 0.0285 & 0.02847 & 0.51 & 0.499 \\
$T_{\text {off }} * T_{\text {off }}$ & 1 & 0.1340 & 0.13400 & 2.39 & 0.166 \\
$I_{\text {peak }} * I_{\text {peak }}$ & 1 & 9.6098 & 9.60979 & 171.49 & 0.000 \\
$W_{f} * W_{f}$ & 1 & 0.0632 & 0.06322 & 1.13 & 0.323 \\
$S V^{*} S V$ & 1 & 0.1160 & 0.11600 & 2.07 & 0.193 \\
$T_{\text {on }} * T_{\text {off }}$ & 1 & 0.0001 & 0.00006 & 0.00 & 0.974 \\
$T_{\text {on }} * I_{\text {peak }}$ & 1 & 0.0619 & 0.06187 & 1.10 & 0.328 \\
$T_{\text {on }} * W_{f}$ & 1 & 0.1104 & 0.11045 & 1.97 & 0.203 \\
$T_{\text {on }} * S V$ & 1 & 0.0084 & 0.00842 & 0.15 & 0.710 \\
$T_{\text {off }} * I_{\text {peak }}$ & 1 & 0.0189 & 0.01889 & 0.34 & 0.580 \\
$T_{\text {off }} * W_{f}$ & 1 & 0.0797 & 0.07965 & 1.42 & 0.272 \\
$T_{\text {off }} * S V$ & 1 & 0.0018 & 0.00177 & 0.03 & 0.864 \\
$I_{\text {peak }} * W_{f}$ & 1 & 0.0005 & 0.00048 & 0.01 & 0.929 \\
$I_{\text {peak }} * S V$ & 1 & 0.0091 & 0.00907 & 0.16 & 0.699 \\
Error & 7 & 0.3922 & 0.05604 & & \\
Total & 26 & 36.6064 & & & \\
\hline
\end{tabular}

\section{Modelling using ANN}

Artificial Neural Networks (ANN) are data-driven algorithms that are used extensively to study different aspects of the machining domain (Imani et al. 2020; Saha et al. 2020). In this paper, ANN is deployed to predict responses in the WEDM process for A286 alloy. The ANN model's construction comprises necessary steps: normalization of datasets, selection of training algorithm, network topology determination, network training, testing, and model validation. 


\subsection{Normalization of datasets}

Data normalization is a process of scaling the range of input and output variables to either $[-1,1]$ or $[0,1]$. In this paper, we carried out normalization to the input/output data by employing Eq. (13) as discussed in the article by Sanjay and Jyothi (2006).

$$
x_{i}=\frac{0.8}{d_{\text {max }}-d_{\text {min }}}\left(d_{i}-d_{\text {min }}\right)+0.1
$$

Where $d_{\max }$ is the maximum value of the response parameter, $d_{\min }$ is the minimum value of the response parameter, and $d_{i}$ is the nominal value of the response parameter.

5.2. Selection of training algorithm, network topology, network training, testing, and validation

The training algorithm proposed for developing the ANN model is a feedforward backpropagation algorithm. The network architecture which commonly executes this algorithm is a multilayer perceptron (MLP). In the present work, the input layer of the MLP has five neurons that correspond to five input features ( $T_{o n}, T_{\text {off }}, I_{p e a k}, W f$, and $\left.S V\right)$. The next layer is the intermediate (hidden) layer, for which the number of neurons is to be specified by trial and error procedure. The last layer is the extreme (output) layer with two neurons corresponding to dual responses (MRR and $S R$ ). Hyperbolic tangent sigmoid transfer function and linear transfer function are incorporated in the intermediate and extreme layer, respectively to map suitably the correlation between the responses and the input features. A Lavenberg-Marquardt algorithm, i.e., trainlm is proposed to train the network on account of its faster convergence rate. Gradient descent learning function, i.e., LEARNGD is chosen to update the weights and biases associated with the network.

To ensure an optimal network structure for maximum performance, it is crucial to quantify the exact number of hidden neurons in the intermediate layer. After comprehensive trial and error, it is identified that the network topology which is most eligible in correlating the responses with the input features must have 9 hidden neurons in the intermediate layer. Hence, the network topology which is considered in this paper is 5-9-2. The strategy adopted during the process of identification of the network is discussed below. 
For establishing the ANN models based on a different number of hidden neurons, a total of 81 samples are fragmented into $70 \%$ (training), 15\% (testing), and 15\% (validation) set. In this work, the performances of the different configured networks' performances (networks with variable hidden neurons in the intermediate layer) are assessed by the scatter plots. For the sake of brevity, scatter plots are provided here only for the selected network topology (5-9-2).

Scatter plots intuitively estimate the quality of model fitment by illustrating the degree of connection between the targets and network outputs. Fig. 4 delivers scatter plots associated with training, testing, validation, and the overall dataset of the selected network. It is observed from the plots that the regression line almost inclines at an angle of $45^{\circ}$ with the network output and the target and exhibits a high correlation co-efficient value, $\mathrm{R}=0.99$ for the training, testing, validation, and overall datasets. Such behavior ensures that the network topology 5-9-2 is hugely proficient in mapping the $M R R$ and $S R$ with the input features. Moreover, it can also be ensured that the model is least overfitted and at the same time has maximum generalization capability.

\section{Comparison between ANN and RSM}

To perform a comparison amid ANN and RSM model predictions, the predictions carried out by the ANN model and RSM-based polynomial regression models are compared with the experimentally obtained averaged responses for 27 experimental runs. It is evident from the plots portrayed in figures (Fig.5 and Fig. 6) that the green dots representing the observed responses and the purple dots representing the ANN predicted responses completely coalesce with each other, thereby demonstrating the accuracy of the ANN model. On the other hand, RSM-based predictionsrepresented by purple dots are slightly deviating from the green dots for almost all the observations except few cases, which depict that the accuracy of RSM-based models is less than the ANN model. 

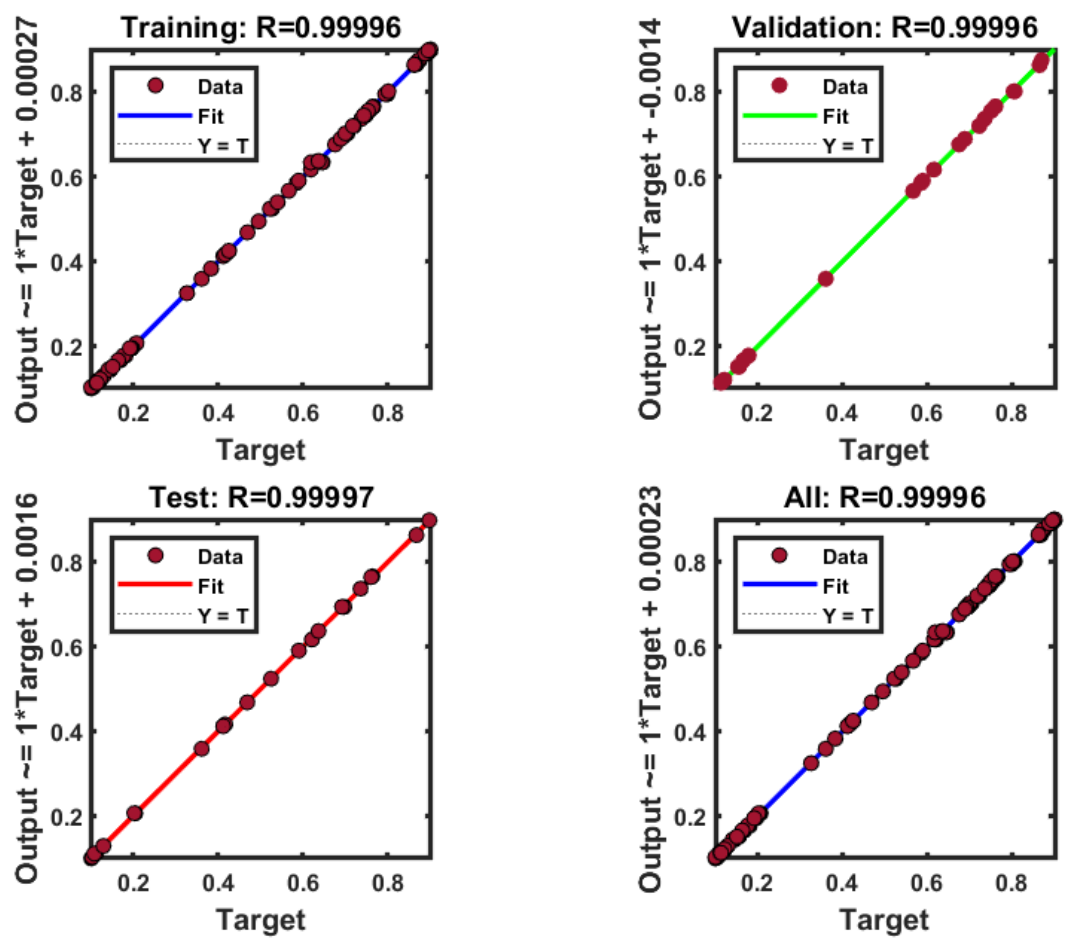

Fig. 4 Training, testing, validation and overall scatter plots for 5-9-2 network.

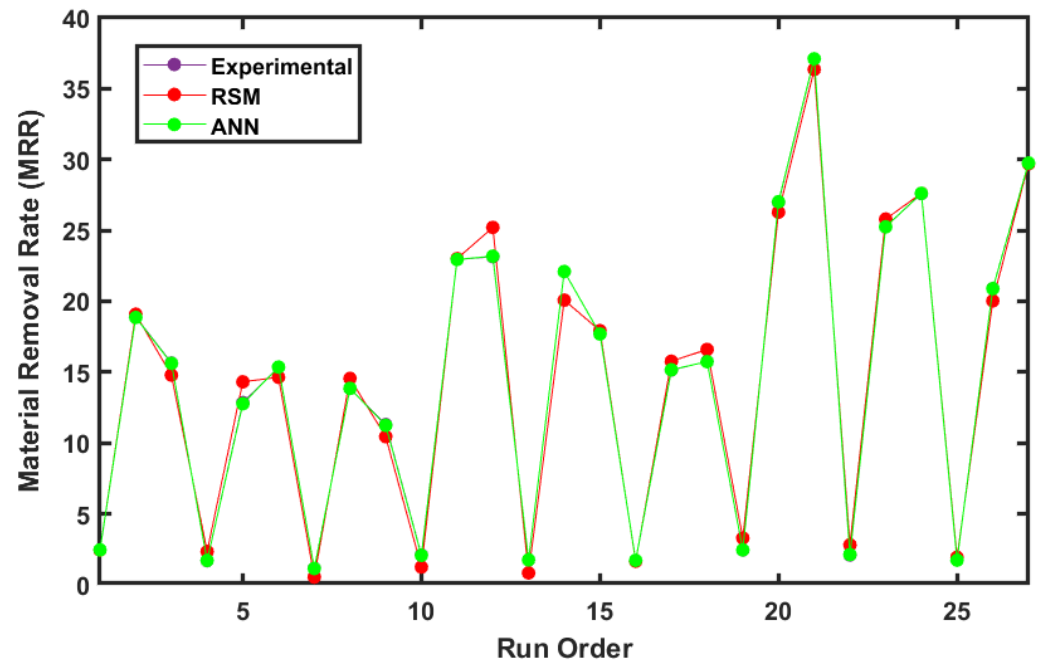

Fig. 5 Plots showing comparison between ANN and RSM predictions for MRR. 


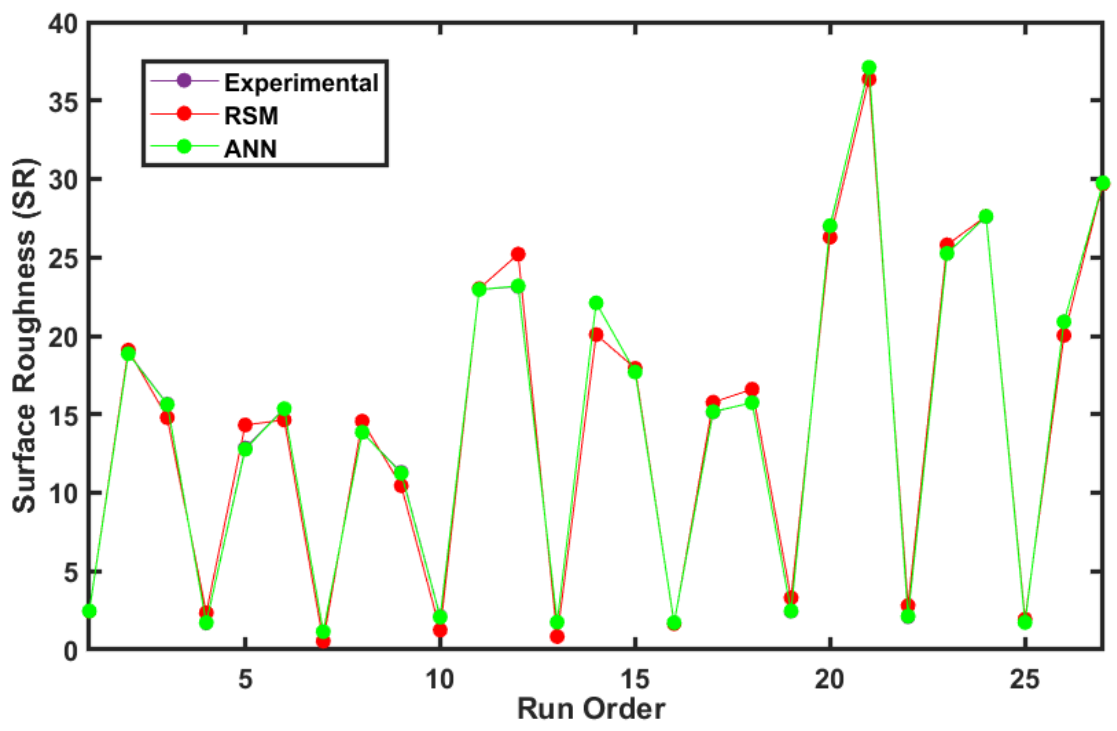

Fig. 6 Plots showing a comparison between ANN and RSM predictions for SR.

\section{Multiobjective Optimization using MOEA/D coupled with TOPSIS}

To carry out the multiobjectiveOptimization, response surface models, as referred to in section 4 are employed to correlate the process parameters with the response parameters. The empirical models of $M R R$ and $S R$ (Eq. (11) \& Eq. (12)) are used as the objective functions.

The optimization is implemented by developing a MATLAB code. The important tuning parameters and their corresponding values are displayed below:

(a) Maximum number of generations $=250$

(b) Population size $=100$

(c) Distribution index $=20$

(d) Crossover probability $=1$

(e) Mutation probability $=1 /$ dimension of problem

(f) Mutation index $=20$

The optimization code is framed for the minimization of objective functions. Thus, MRR in eqn. 1 is changed to $(-M R R)$ during the Optimization while on the contrary,SR in eqn. 2 remains 
the same. 100 optimal solutions are achieved after running the Optimization for the dual objectives (MRR \& SR) with the parameter bounds as constraints. Those 100 optimal solutions are an integral part of the Pareto front, as portrayed in Fig. 7.

Since each solution in the Pareto front can be accepted as the candidate solution based on the operator's requirement. Thus, pointing out the best solution is a bit complicated task. To tackle such an ambiguous situation, a decision-making technique, i.e., TOPSIS, is intervened in this work to select the best optimal solution. In the TOPSIS algorithm's execution, weights are allotted to MRR and SR on the basis of relative preferences. In this paper, equal weights are allotted to the two performance parameters to establish the weighted normalized decision matrix. Then the positive ideal solution and negative ideal solution are identified according to the TOPSIS algorithm. Finally, each solution's relative closeness coefficient $\left(C C_{i}\right)$ of the Pareto front is calculated based on the two distant measures (separation from a positive ideal solution, $E_{i}^{+}$and separation from a negative ideal solution, $E_{i}^{-}$). The measurement of relative closeness coefficient plays a pivotal role in assigning the ranks of the Pareto solutions. To claim for top rank, it is essential that the solution should have the maximum relative closeness coefficient value.

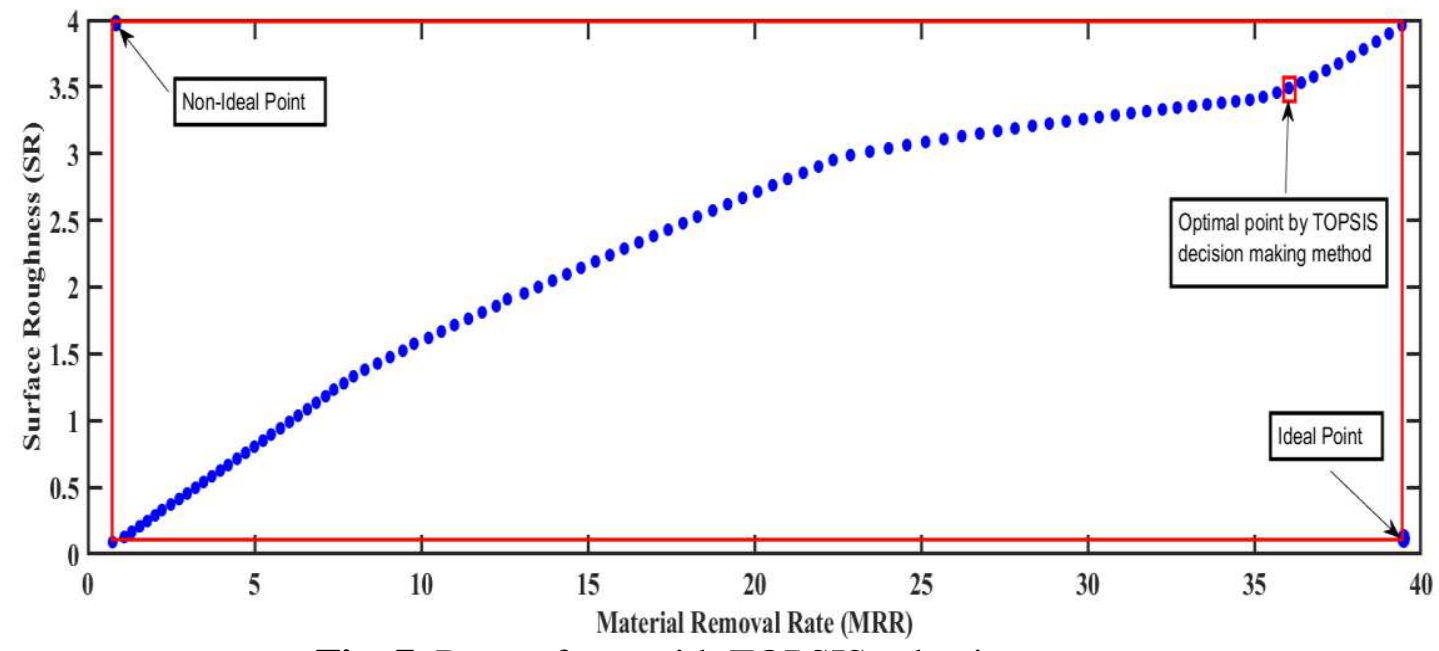

Fig. 7 Pareto front with TOPSIS selection.

Table (A) (see Appendix) reported all the 100 Pareto optimal solutions along with the vital TOPSIS parameters and their rankings. It is evident that solution number 91 achieves the maximum relative closeness coefficient of 0.540115634 and holds the first rank (Table (A)). Thus, solution number 91 draws the most priority to be the best optimal solution. Furthermore, 
for the sake of visualization, this particular solution is also indicated by a rectangular block on the Pareto front, as illustrated in Fig.7. The values of the response parameters corresponding to the optimal solution are $\mathrm{MRR}=36.04$ and $\mathrm{SR}=3.49$, respectively.

Furthermore, a confirmatory experiment has been conducted to validate the responses at the optimal input parametric setting. The deviations between the optimal responses and the affirmative experimental responses are less than 1\%, as shown in Table 5. Finally, it is intended to check the robustness of the proposed approach. Because of the above, Optimization of dual responses is carried out with the proposed optimization approach and then compared with the optimization results put forth by the other technique in the paper by Devarasiddappa and Chandrasekaran 2020. In both methods, the computational procedure is carried out by allotting equal weightage for both the responses. It is observed that the proposed method is far more effective and robust in optimizing the dual responses. The results are reported in Table 6.

Table 5 Validation of the proposed optimization approach with experimental results.

\begin{tabular}{ccccc}
\hline $\begin{array}{c}\text { Response } \\
\text { parameter }\end{array}$ & $\begin{array}{c}\text { Optimal parameters by the } \\
\text { proposed method }\end{array}$ & $\begin{array}{c}\text { Optimum values by } \\
\text { MOEA/D-TOPSIS }\end{array}$ & $\begin{array}{c}\text { Experimental } \\
\text { values }\end{array}$ & Error (\%) \\
\hline $\begin{array}{c}\text { MRR } \\
T_{\text {on }}=129.9972(130) \mu \mathrm{s},\end{array}$ & 36.04 & 36.24 & 0.55 \\
$T_{\text {off }}=52.5902(52) \mu \mathrm{s}$, & & & \\
& $I_{\text {peak }}=12 \mathrm{~A}$, & 3.49 & 3.51 & 0.57 \\
$S R(\mu \mathrm{m})$ & $W_{f}=5 \mathrm{~m} / \mathrm{min}$, & & & \\
& $S V=30$ volt & & &
\end{tabular}


Table 6 Validation of the proposed optimization approach with other technique (Devarasiddappa and Chandrasekaran 2020)

\begin{tabular}{|c|c|c|c|c|}
\hline $\begin{array}{l}\text { Response } \\
\text { parameter }\end{array}$ & $\begin{array}{l}\text { Optimal parameters } \\
\text { (PBMOO-TLBO) }\end{array}$ & $\begin{array}{c}\text { Optimal parameters } \\
\text { (MOEA/D- } \\
\text { TOPSIS })\end{array}$ & $\begin{array}{l}\text { Optimal value } \\
\text { (PBMOO- } \\
\text { TLBO) }\end{array}$ & $\begin{array}{c}\text { Optimal value } \\
\text { (MOEA/D-TOPSIS) }\end{array}$ \\
\hline $\begin{array}{l}\text { MRR } \\
\text { (g/min) }\end{array}$ & $\begin{array}{l}\mathrm{T}_{\text {on }}=27.82 \mu \mathrm{s}, \\
\mathrm{T}_{\text {off }}=6.05 \mu \mathrm{s}\end{array}$ & $\begin{array}{c}\mathrm{T}_{\text {on }}=13 \mu \mathrm{s}, \\
\mathrm{T}_{\text {off }}=4 \mu \mathrm{s},\end{array}$ & 0.0585 & 0.0530 \\
\hline & $\mathrm{I}_{\text {peak }}=3.78 \mathrm{~A}$ & $\mathrm{I}_{\text {peak }}=5 \mathrm{~A}$ & 7.4095 & 3.4646 \\
\hline $\mathrm{SR}(\mu \mathrm{m})$ & $\mathrm{WS}=1275 \mathrm{rpm}$ & $\mathrm{WS}=1162 \mathrm{rpm}$ & & \\
\hline
\end{tabular}

\section{Conclusion}

Prediction of MRR and SR is carried out by RSM and ANN model for WEDM of A286 Superalloy. Furthermore, it is intended to compare the predictive capability of the two models. ANOVA analysis is performed to depict the significant parameters affecting the responses. Owing to the scarce literature that incorporates the decomposition-based multiobjective evolutionary algorithms in the optimization of WEDM responses. Additionally, other researchers in the WEDM have not mentioned any suitable procedure to identify the best optimal point out of the Pareto optimal solutions obtained by evolutionary algorithms. Thus, the present paper is novel in the sense that it incorporates a multiobjective evolutionary algorithm based on decomposition (MOEA/D) in conjunction with an MCDM technique namely a technique for order preference by similarity to ideal solution (TOPSIS) to identify the optimal machining condition for suitably bridging the research gaps. Following are the concluding remarks which are mentioned below:

1. ANN model is relatively more accurate than RSM in predicting responses like the material removal rate $(M R R)$ and surface roughness $(S R)$.

2. From ANOVA analysis, we identified that $I_{\text {peak }}$ is the most momentous individual parameter that affects the MRR followed by $T_{o n}$ and $W_{f}$.The interacting parameters found to be momentous for MRR are $\left(T_{o n} * I_{p e a k}\right)$ and $\left(T_{o n} * W_{f}\right)$. Again, from the ANOVA analysis for $S R, I_{p e a k}$ is the sole 
parameter that is found to be momentous. However, there is no evidence of any momentous interacting parameters affecting the $S R$.

2. MOEA/D is integrated with TOPSIS to determine the optimal parametric setting that simultaneously optimizes MRR and SR. The Pareto front obtained by MOEA/D comprises of 100 trade-off solutions. Eventually, TOPSIS has been implemented to select the best compromise solution from the Pareto solutions. The best parametric combination recommended by the combined approach is $T_{o n}=130 \mu \mathrm{s}, T_{o f f}=52 \mu \mathrm{s}, I_{p e a k}=12 \mathrm{~A}, W_{f}=5 \mathrm{~m} / \mathrm{min}$ and $S V=30$ volt.

3. Finally a confirmatory experiment has been conducted to validate the responses at the optimal input parametric setting. The deviations among the optimal responses and the confirmatory experimental responses are found to be less than $1 \%$.

4. To validate the robustness of the proposed optimization methodology, optimization problem from published literature (Devarasiddappa and Chandrasekaran 2020) is solved with the proposed optimization methodology and the results are compared with the results furnished in the paper. The results obtained by the proposed approach is found to be more optimal than the results provided in the paper.

Further research might analyze other performance parameters such as micro-hardness, recast layer thickness, residual stress, etc. Moreover, modeling the different performance parameters can also be carried out by other advanced modeling techniques.

The proposed optimization technique can be used to optimize other WEDM performance parameters. The proposed optimization technique can also be exploited in other manufacturing processes.

\section{Declaration}

Funding Not Applicable

Conflicts of interest The authors declare that they have no conflict of interest.

Availability of data and material Not applicable

Code availability Not applicable 
Ethical approval This article does not contain any studies with human participants or animals performed by any of the authors.

Consent to participate Not applicable.

Consent for publication Not applicable

This research received no specific grant from any funding agency in public, commercial or notfor-profit sectors.

\section{References}

Khalid FA, Hussain N, Shahid KA (1999) Microstructure and morphology of high temperature oxidation in superalloys. Mater Sci Eng A 265: 87-94.

Pollock TM, Tin S (2006) Nickel-based superalloys for advanced turbine engines: chemistry, microstructure and properties. J Propuls Power 22(2): 361-374.

Sharma P, Chakradhar D, Narendranath S (2015) Evaluation of WEDM performance characteristics of Inconel 706 for turbine disk application. Mater Des 88: 558-566.

Majumder H, Maity K (2018) Application of GRNN and multivariate hybrid approach to predict and optimize WEDM responses for Ni-Ti shape memory alloy. Appl Soft Comput 70: 665-679.

Saha A, Mondal SC (2017) Experimental investigation and modelling of WEDM process for machining nano-structured hardfacing material. J Braz Soc 39(9): 3439-3455.

Saha A, Mondal SC (2016) Multi-objective optimization in WEDM process of nanostructured hardfacing materials through hybrid techniques. Measurement 94: 46-59.

Saha P, Tarafdar D, Pal SK, Saha P, Srivastava AK, Das K (2013) Multi-objective optimization in wire-electro-discharge machining of $\mathrm{TiC}$ reinforced composite through Neuro-Genetic technique. Appl Soft Comput 13(4): 2065-2074.

Mandal A, Dixit AR, Das AK, Mandal N (2016) Modeling and optimization of machining nimonic C-263 superalloy using multicut strategy in WEDM. Mater Manuf Process 31(7): 860868. 
Ramakrishnan R, Karunamoorthy L (2008) Modeling and multi-response optimization of Inconel 718 on machining of CNC WEDM process. J Mater Process Technol 207(1-3): 343-349.

Tonday HR, Tigga AM (2019) An empirical evaluation and optimization of performance parameters of wire electrical discharge machining in cutting of Inconel 718. Measurement 140: 185-196.

Khan NZ, Khan ZA, Siddiquee AN, Chanda AK (2014) Investigations on the effect of wire EDM process parameters on surface integrity of HSLA: A multi-performance characteristics optimization. Prod Manuf Res 2(1): 501-518.

Tarng YS, Ma SC, Chung LK (1995) Determination of optimal cutting parameters in wire electrical discharge machining. Int J Mach Tools Manuf 35(12): 1693-1701.

Sadeghi M, Razavi H, Esmaeilzadeh A, Kolahan F (2011) Optimization of cutting conditions in WEDM process using regression modelling and Tabu-search algorithm. Proc Inst Mech Eng B J Eng Manuf 225(10): 1825-1834.

Rao MS, Venkaiah N (2017) A modified cuckoo search algorithm to optimize wire-EDM process while machining Inconel-690. J Braz Soc Mech Sci \& Eng 39(5): 1647-1661.

Nayak BB, Mahapatra SS (2016) Optimization of WEDM process parameters using deep cryotreated Inconel 718 as work material. Eng Sci Technol Int J 19(1): 161-170.

Kuriakose S, Shunmugam MS (2005) Multi-objective optimization of wire-electro discharge machining process by non-dominated sorting genetic algorithm. J Mater Process Technol 170(12): 133-141.

Garg MP, Jain A, Bhushan G (2012) Modelling and multi-objective optimization of process parameters of wire electrical discharge machining using non-dominated sorting genetic algorithm-II. Proc Inst Mech Eng B J Eng Manuf 226(12): 1986-2001.

Musavi SH, Davoodi B, Niknam SA (2018) Environmental-friendly turning of A286 superalloy. J Manuf Process 32: 734-743.

Alphonsa J, Raja VS, Mukherjee S (2015) Development of highly hard and corrosion resistant A286 stainless steel through plasma nitrocarburizing process. Surf Coat Technol 280: 268-276. 
Ngatchou P, Zarei A, El-Sharkawi A (2005) Pareto multi objective optimization. In Proceedings of the 13th International Conference on, Intelligent Systems Application to Power Systems (pp. 84-91). IEEE.

Dauw DF, Albert L (1992) About the evolution of wire tool performance in wire EDM. CIRP Ann Manuf Technol 41(1): 221-225.

Ramakrishnan R, Karunamoorthy L (2006) Multi response optimization of wire EDM operations using robust design of experiments. Int J Adv Manuf Technol 29(1-2): 105-112.

Chalisgaonkar, R, Kumar J (2015) Multi-response optimization and modeling of trim cut WEDM operation of commercially pure titanium (CPTi) considering multiple user's preferences. Eng Sci Technol Int J 18(2): 125-134.

Zhang Q, Li H (2007) MOEA/D: A multiobjective evolutionary algorithm based on decomposition. IEEE Trans Evol Comput 11(6): 712-731.

Wang L, Zhang Q, Zhou A, Gong M, Jiao L (2015) Constrained subproblems in a decomposition-based multiobjective evolutionary algorithm. IEEE Trans Evol Comput 20(3): 475-480.

Hwang CL, Yoon K (1981) Methods for multiple attribute decision making. In Multiple attribute decision making. Springer, Berlin, Heidelberg, pp 58-191.

Imani L, Rahmani Henzaki A, Hamzeloo R, Davoodi B (2020) Modeling and optimizing of cutting force and surface roughness in milling process of Inconel 738 using hybrid ANN and GA. Proc Inst Mech Eng B J Eng Manuf 234(5): 920-932.

Saha S, Maity SR, Dey S (2020) Artificial-Neural-Network-Based Uncertain Material Removal Rate by Turning. In Reliability, Safety and Hazard Assessment for Risk-Based Technologies. Springer, Singapore, pp 591-596.

Sanjay C, Jyothi C (2006) A study of surface roughness in drilling using mathematical analysis and neural networks. Int J Adv Manuf Technol 29(9-10): 846-852. 
Devarasiddappa D, Chandrasekaran M (2020) Experimental investigation and optimization of sustainable performance measures during wire-cut EDM of Ti-6Al-4V alloy employing preference-based TLBO algorithm. Mater Manuf Process 35(11): 1204-1.

\section{Appendix}

Table (A) Allocation of ranks to non-dominated optimal solutions exploiting TOPSIS method.

\begin{tabular}{|c|c|c|c|c|c|c|}
\hline $\begin{array}{l}\text { Solution } \\
\text { Number }\end{array}$ & $M R R$ & $S R$ & $\begin{array}{c}\text { Negative Ideal } \\
\text { Solution }\end{array}$ & $\begin{array}{c}\text { Positive Ideal } \\
\text { Solution }\end{array}$ & $\begin{array}{c}\text { Relative } \\
\text { closeness } \\
\text { coefficient }\end{array}$ & Ranking \\
\hline \multirow{3}{*}{1} & 0.739106 & 0.08939 & & & & \\
\hline & 033 & 5853 & 0.07857374 & 0.088855723 & 0.469294582 & 32 \\
\hline & 1.087873 & 0.12720 & & & & \\
\hline \multirow[t]{2}{*}{2} & 319 & 769 & 0.077810329 & 0.088058138 & 0.469108627 & 33 \\
\hline & 1.315406 & 0.16633 & & & & \\
\hline \multirow[t]{2}{*}{3} & 827 & 1678 & 0.077023409 & 0.087546202 & 0.468029356 & 34 \\
\hline & 1.554208 & 0.20742 & & & & \\
\hline \multirow[t]{2}{*}{4} & 238 & 3309 & 0.076200923 & 0.087016861 & 0.466866544 & 35 \\
\hline & 1.780239 & 0.24635 & & & & \\
\hline \multirow[t]{2}{*}{5} & 801 & 8411 & 0.075425499 & 0.086523484 & 0.465736169 & 36 \\
\hline & 2.013398 & 0.28864 & & & & \\
\hline \multirow[t]{2}{*}{6} & 287 & 9734 & 0.074586562 & 0.086024497 & 0.464392443 & 38 \\
\hline & 2.219003 & 0.32962 & & & & \\
\hline \multirow[t]{2}{*}{7} & 806 & 931 & 0.073775617 & 0.085596216 & 0.462915033 & 39 \\
\hline & 2.486775 & 0.37090 & & & & \\
\hline \multirow[t]{2}{*}{8} & 562 & 3562 & 0.072969938 & 0.085034484 & 0.461822127 & 40 \\
\hline & 2.738439 & 0.41182 & & & & \\
\hline \multirow[t]{2}{*}{9} & 894 & 5163 & 0.072175012 & 0.084518126 & 0.460613738 & 41 \\
\hline & 2.978307 & 0.45335 & & & & \\
\hline \multirow[t]{2}{*}{10} & 248 & 4648 & 0.071371314 & 0.084038854 & 0.459244816 & 43 \\
\hline & 3.227068 & 0.49614 & & & & \\
\hline \multirow[t]{2}{*}{11} & 473 & 2999 & 0.070549015 & 0.083551165 & 0.457812668 & 44 \\
\hline & 3.467761 & 0.53952 & & & & \\
\hline \multirow[t]{2}{*}{12} & 665 & 8684 & 0.069718773 & 0.083093372 & 0.45623843 & 45 \\
\hline & 3.719993 & 0.58207 & & & & \\
\hline 13 & 909 & 1247 & 0.068913877 & 0.082617747 & 0.454782143 & 46 \\
\hline
\end{tabular}




\begin{tabular}{|c|c|c|c|c|c|c|}
\hline & 3.972165 & 0.62567 & & & & \\
\hline \multirow[t]{2}{*}{14} & 02 & 1649 & 0.068093983 & 0.082155513 & 0.453206066 & 48 \\
\hline & 4.206123 & 0.66643 & & & & \\
\hline \multirow[t]{2}{*}{15} & 123 & 2293 & 0.067333001 & 0.081737465 & 0.451685722 & 49 \\
\hline & 4.473329 & 0.71390 & & & & \\
\hline \multirow[t]{2}{*}{16} & 935 & 217 & 0.066452677 & 0.081274925 & 0.449832502 & 50 \\
\hline & 4.730559 & 0.75799 & & & & \\
\hline \multirow[t]{2}{*}{17} & 99 & 4508 & 0.065645117 & 0.08083693 & 0.448144454 & 52 \\
\hline & 4.994184 & 0.80411 & & & & \\
\hline \multirow[t]{2}{*}{18} & 605 & 7204 & 0.064806703 & 0.080403833 & 0.446294774 & 53 \\
\hline & 5.253440 & 0.84956 & & & & \\
\hline \multirow[t]{2}{*}{19} & 27 & 4483 & 0.063988635 & 0.079991131 & 0.444427969 & 54 \\
\hline & 5.497787 & 0.89537 & & & & \\
\hline \multirow[t]{2}{*}{20} & 079 & 04 & 0.063165953 & 0.079626439 & 0.442362174 & 56 \\
\hline & 5.774901 & 0.94154 & & & & \\
\hline \multirow[t]{2}{*}{21} & 646 & 5371 & 0.062357882 & 0.079203148 & 0.440501753 & 57 \\
\hline & 6.045463 & 0.98912 & & & & \\
\hline \multirow[t]{2}{*}{22} & 912 & 7396 & 0.061529077 & 0.078815125 & 0.438415524 & 58 \\
\hline & 6.306000 & 1.03638 & & & & \\
\hline \multirow[t]{2}{*}{23} & 005 & 3137 & 0.060712305 & 0.078462698 & 0.436229952 & 60 \\
\hline & 6.584268 & 1.08442 & & & & \\
\hline \multirow[t]{2}{*}{24} & 035 & 2038 & 0.05989935 & 0.078089815 & 0.434087343 & 61 \\
\hline & 6.849772 & 1.13295 & & & & \\
\hline \multirow[t]{2}{*}{25} & 357 & 7583 & 0.059081452 & 0.07776358 & 0.43173984 & 64 \\
\hline & 7.132317 & 1.18164 & & & & \\
\hline \multirow[t]{2}{*}{26} & 474 & 3405 & 0.058282005 & 0.077416682 & 0.429495719 & 66 \\
\hline & 7.375351 & 1.23177 & & & & \\
\hline \multirow[t]{2}{*}{27} & 567 & 2349 & 0.057443381 & 0.0771817 & 0.426691525 & 68 \\
\hline & 7.678654 & 1.27941 & & & & \\
\hline \multirow[t]{2}{*}{28} & 949 & 4547 & 0.056703345 & 0.076816246 & 0.424681836 & 70 \\
\hline & 7.966335 & 1.33153 & & & & \\
\hline \multirow[t]{2}{*}{29} & 079 & 2833 & 0.055881485 & 0.076531395 & 0.422024543 & 73 \\
\hline & 8.309090 & 1.38040 & & & & \\
\hline \multirow[t]{2}{*}{30} & 314 & 2271 & 0.055177957 & 0.076124429 & 0.420235755 & 75 \\
\hline & 8.688870 & 1.42722 & & & & \\
\hline \multirow[t]{2}{*}{31} & 918 & 4303 & 0.054562352 & 0.075642172 & 0.41905112 & 77 \\
\hline & 9.067204 & 1.47483 & & & & \\
\hline \multirow[t]{2}{*}{32} & 249 & 3081 & 0.053954449 & 0.075188012 & 0.417790155 & 78 \\
\hline & 9.450813 & 1.52255 & & & & \\
\hline \multirow[t]{2}{*}{33} & 258 & 8399 & 0.053373617 & 0.074743448 & 0.416600373 & 80 \\
\hline & 9.784220 & 1.57495 & & & & \\
\hline 34 & 977 & 4642 & 0.052686235 & 0.074463091 & 0.414365035 & 83 \\
\hline 35 & 10.22229 & 1.61879 & 0.052280544 & 0.073913752 & 0.414286109 & 85 \\
\hline
\end{tabular}




\begin{tabular}{|c|c|c|c|c|c|c|}
\hline & 211 & 7704 & & & & \\
\hline & 10.60390 & 1.66689 & & & & \\
\hline \multirow[t]{2}{*}{36} & 286 & 3312 & 0.051772034 & 0.073539194 & 0.413147608 & 87 \\
\hline & 10.99682 & 1.71520 & & & & \\
\hline \multirow[t]{2}{*}{37} & 496 & 2022 & 0.051300126 & 0.073165005 & 0.412164639 & 89 \\
\hline & 11.41775 & 1.76230 & & & & \\
\hline \multirow[t]{2}{*}{38} & 318 & 9872 & 0.050911085 & 0.072745028 & 0.41171507 & 91 \\
\hline & 11.83153 & 1.81020 & & & & \\
\hline \multirow{2}{*}{39} & 63 & 735 & 0.050533517 & 0.072370278 & 0.411163196 & 93 \\
\hline & 12.25162 & 1.85740 & & & & \\
\hline \multirow[t]{2}{*}{40} & 891 & 804 & 0.050209598 & 0.071999632 & 0.410849475 & 94 \\
\hline & 12.58445 & 1.91015 & & & & \\
\hline \multirow[t]{2}{*}{41} & 649 & 3311 & 0.049716654 & 0.071882625 & 0.408856487 & 100 \\
\hline & 13.09377 & 1.95278 & & & & \\
\hline \multirow[t]{2}{*}{42} & 909 & 8896 & 0.049653459 & 0.071337066 & 0.4103913 & 97 \\
\hline & 13.51352 & 2.00035 & & & & \\
\hline \multirow[t]{2}{*}{43} & 744 & 2711 & 0.049430146 & 0.071044154 & 0.410296188 & 99 \\
\hline & 13.94220 & 2.04815 & & & & \\
\hline \multirow[t]{2}{*}{44} & 94 & 9565 & 0.049252371 & 0.070762132 & 0.410386827 & 98 \\
\hline & 14.37006 & 2.09618 & & & & \\
\hline \multirow[t]{2}{*}{45} & 436 & 6066 & 0.049108229 & 0.070510215 & 0.410540612 & 96 \\
\hline & 14.79301 & 2.14377 & & & & \\
\hline \multirow[t]{2}{*}{46} & 499 & 1036 & 0.049002098 & 0.070288405 & 0.410779541 & 95 \\
\hline & 15.22860 & 2.19167 & & & & \\
\hline \multirow[t]{2}{*}{47} & 538 & 0688 & 0.048949138 & 0.070073531 & 0.411258948 & 92 \\
\hline & 15.66256 & 2.23940 & & & & \\
\hline \multirow[t]{2}{*}{48} & 351 & 1823 & 0.048935718 & 0.069886639 & 0.411839317 & 90 \\
\hline & 16.09551 & 2.28766 & & & & \\
\hline \multirow[t]{2}{*}{49} & 498 & 5814 & 0.048952601 & 0.069735655 & 0.412446883 & 88 \\
\hline & 16.53525 & 2.33504 & & & & \\
\hline \multirow[t]{2}{*}{50} & 137 & 5675 & 0.049032851 & 0.069588808 & 0.413354958 & 86 \\
\hline & 16.97403 & 2.38281 & & & & \\
\hline \multirow[t]{2}{*}{51} & 702 & 9386 & 0.049145685 & 0.069476628 & 0.414303886 & 84 \\
\hline & 17.40961 & 2.43015 & & & & \\
\hline \multirow[t]{2}{*}{52} & 793 & 426 & 0.049297845 & 0.069391719 & 0.415351135 & 82 \\
\hline & 17.85765 & 2.47845 & & & & \\
\hline \multirow[t]{2}{*}{53} & 239 & 8625 & 0.04949917 & 0.069327779 & 0.416565187 & 81 \\
\hline & 18.28909 & 2.52689 & & & & \\
\hline \multirow[t]{2}{*}{54} & 385 & 4074 & 0.049707851 & 0.069321522 & 0.417609956 & 79 \\
\hline & 18.74839 & 2.57345 & & & & \\
\hline \multirow[t]{2}{*}{55} & 065 & 1848 & 0.050029003 & 0.069271757 & 0.419351924 & 76 \\
\hline & 19.19570 & 2.62087 & & & & \\
\hline 56 & 187 & 244 & 0.050355303 & 0.069282376 & 0.420898362 & 74 \\
\hline
\end{tabular}




\begin{tabular}{|c|c|c|c|c|c|c|}
\hline & 19.64440 & 2.66825 & & & & \\
\hline \multirow[t]{2}{*}{57} & 204 & 3204 & 0.05072174 & 0.069318886 & 0.422538113 & 72 \\
\hline & 20.09602 & 2.71555 & & & & \\
\hline \multirow[t]{2}{*}{58} & 771 & 9934 & 0.051131007 & 0.069378563 & 0.424290013 & 71 \\
\hline & 20.54802 & 2.76296 & & & & \\
\hline \multirow[t]{2}{*}{59} & 078 & 1532 & 0.05157561 & 0.06946793 & 0.426091389 & 69 \\
\hline & 20.99612 & 2.81038 & & & & \\
\hline \multirow[t]{2}{*}{60} & 374 & 9129 & 0.052046689 & 0.06959183 & 0.427879998 & 67 \\
\hline & 21.46524 & 2.85624 & & & & \\
\hline \multirow[t]{2}{*}{61} & 787 & 3181 & 0.052608625 & 0.069689663 & 0.430166485 & 65 \\
\hline & 21.92207 & 2.90319 & & & & \\
\hline \multirow[t]{2}{*}{62} & 998 & 4153 & 0.053167919 & 0.069850854 & 0.432193543 & 63 \\
\hline & 22.36085 & 2.95222 & & & & \\
\hline \multirow[t]{2}{*}{63} & 288 & 4869 & 0.05370434 & 0.070098551 & 0.433789061 & 62 \\
\hline & 22.88115 & 2.98859 & & & & \\
\hline \multirow[t]{2}{*}{64} & 096 & 7251 & 0.054539625 & 0.070056464 & 0.437731433 & 59 \\
\hline & 23.46295 & 3.01497 & & & & \\
\hline \multirow[t]{2}{*}{65} & 433 & 1953 & 0.055600353 & 0.069795639 & 0.443398166 & 55 \\
\hline & 24.02539 & 3.03952 & & & & \\
\hline \multirow[t]{2}{*}{66} & 028 & 1678 & 0.056647999 & 0.069554329 & 0.448866513 & 51 \\
\hline & 24.57377 & 3.06363 & & & & \\
\hline \multirow[t]{2}{*}{67} & 381 & 7555 & 0.057681993 & 0.069348029 & 0.454081579 & 47 \\
\hline & 25.13755 & 3.08734 & & & & \\
\hline \multirow[t]{2}{*}{68} & 669 & 7119 & 0.058765073 & 0.069143458 & 0.459430442 & 42 \\
\hline & 25.68536 & 3.10859 & & & & \\
\hline \multirow[t]{2}{*}{69} & 6 & 166 & 0.059839739 & 0.068938243 & 0.464673681 & 37 \\
\hline & 26.22166 & 3.13039 & & & & \\
\hline \multirow[t]{2}{*}{70} & 749 & 5218 & 0.060895943 & 0.068779979 & 0.469601004 & 31 \\
\hline & 26.76134 & 3.15014 & & & & \\
\hline \multirow[t]{2}{*}{71} & 302 & 2887 & 0.061980317 & 0.068605224 & 0.474633839 & 30 \\
\hline & 27.29943 & 3.17008 & & & & \\
\hline \multirow[t]{2}{*}{72} & 426 & 8827 & 0.063068405 & 0.06845997 & 0.479504177 & 29 \\
\hline & 27.81783 & 3.18898 & & & & \\
\hline \multirow[t]{2}{*}{73} & 497 & 1876 & 0.064125755 & 0.068337106 & 0.484103656 & 28 \\
\hline & 28.34105 & 3.20809 & & & & \\
\hline \multirow[t]{2}{*}{74} & 814 & 8994 & 0.065199653 & 0.068237034 & 0.488618645 & 27 \\
\hline & 28.84778 & 3.22450 & & & & \\
\hline \multirow[t]{2}{*}{75} & 52 & 0209 & 0.066255697 & 0.068122203 & 0.49305501 & 26 \\
\hline & 29.35583 & 3.24156 & & & & \\
\hline \multirow[t]{2}{*}{76} & 378 & 8354 & 0.067316964 & 0.068040416 & 0.497327623 & 25 \\
\hline & 29.86710 & 3.25834 & & & & \\
\hline 77 & 849 & 2613 & 0.06839191 & 0.067972283 & 0.501538629 & 24 \\
\hline 78 & 30.34421 & 3.27365 & 0.069400833 & 0.067921854 & 0.505385052 & 23 \\
\hline
\end{tabular}




\begin{tabular}{|c|c|c|c|c|c|c|}
\hline & 904 & 2511 & & & & \\
\hline & 30.82894 & 3.28879 & & & & \\
\hline \multirow[t]{2}{*}{79} & 853 & 7574 & 0.070431534 & 0.0678822 & 0.509215765 & 22 \\
\hline & 31.30194 & 3.30325 & & & & \\
\hline \multirow[t]{2}{*}{80} & 471 & 2749 & 0.071442171 & 0.067856122 & 0.512871834 & 21 \\
\hline & 31.77093 & 3.31771 & & & & \\
\hline \multirow[t]{2}{*}{81} & 296 & 9762 & 0.072447087 & 0.067851313 & 0.516378569 & 20 \\
\hline & 32.24173 & 3.33105 & & & & \\
\hline \multirow[t]{2}{*}{82} & 404 & 0257 & 0.073463328 & 0.06784148 & 0.519892628 & 19 \\
\hline & 32.68958 & 3.34409 & & & & \\
\hline \multirow[t]{2}{*}{83} & 306 & 3459 & 0.0744314 & 0.067856283 & 0.52310501 & 18 \\
\hline & 33.13922 & 3.35667 & & & & \\
\hline \multirow[t]{2}{*}{84} & 965 & 7687 & 0.075407587 & 0.067877717 & 0.526275794 & 17 \\
\hline & 33.58293 & 3.36881 & & & & \\
\hline \multirow[t]{2}{*}{85} & 656 & 9079 & 0.076374054 & 0.067909691 & 0.529332351 & 16 \\
\hline & 34.01659 & 3.38052 & & & & \\
\hline \multirow[t]{2}{*}{86} & 551 & 4256 & 0.077321194 & 0.067953337 & 0.532241911 & 13 \\
\hline & 34.44490 & 3.39177 & & & & \\
\hline \multirow[t]{2}{*}{87} & 657 & 696 & 0.078259471 & 0.068005382 & 0.535053156 & 10 \\
\hline & 34.86447 & 3.40300 & & & & \\
\hline \multirow[t]{2}{*}{88} & 42 & 9889 & 0.079179692 & 0.068075062 & 0.537705507 & 7 \\
\hline & 35.26683 & 3.42432 & & & & \\
\hline \multirow[t]{2}{*}{89} & 147 & 934 & 0.080034351 & 0.068367314 & 0.539308981 & 4 \\
\hline & 35.67778 & 3.45672 & & & & \\
\hline \multirow[t]{2}{*}{90} & 798 & 9488 & 0.080883701 & 0.068894153 & 0.540024435 & 2 \\
\hline & 36.03618 & 3.49123 & & & & \\
\hline \multirow[t]{2}{*}{91} & 459 & 6348 & 0.081615543 & 0.069491994 & 0.540115634 & 1 \\
\hline & 36.40985 & 3.53139 & & & & \\
\hline \multirow[t]{2}{*}{92} & 967 & 6742 & 0.082377743 & 0.070212114 & 0.539863819 & 3 \\
\hline & 36.78129 & 3.57575 & & & & \\
\hline \multirow[t]{2}{*}{93} & 754 & 9501 & 0.083136639 & 0.071030102 & 0.539264425 & 5 \\
\hline & 37.15574 & 3.62340 & & & & \\
\hline \multirow[t]{2}{*}{94} & 935 & 9505 & 0.083908442 & 0.071926236 & 0.538445247 & 6 \\
\hline & 37.52782 & 3.67372 & & & & \\
\hline \multirow[t]{2}{*}{95} & 572 & 9308 & 0.084683808 & 0.072888767 & 0.53742733 & 8 \\
\hline & 37.90134 & 3.72689 & & & & \\
\hline \multirow[t]{2}{*}{96} & 763 & 6574 & 0.085472982 & 0.073920341 & 0.536239414 & 9 \\
\hline & 38.27881 & 3.78140 & & & & \\
\hline \multirow[t]{2}{*}{97} & 658 & 633 & 0.086284872 & 0.074989986 & 0.535017503 & 11 \\
\hline & 38.66108 & 3.83916 & & & & \\
\hline \multirow[t]{2}{*}{98} & 37 & 9658 & 0.087121002 & 0.076136333 & 0.533642193 & 12 \\
\hline & 39.04428 & 3.89893 & & & & \\
\hline 99 & 104 & 8994 & 0.087975125 & 0.077334128 & 0.532185123 & 14 \\
\hline
\end{tabular}


100

$39.43157 \quad 3.96025$

$439 \quad 9309$

$0.088855723 \quad 0.07857374$

0.530705418

15 
Figures

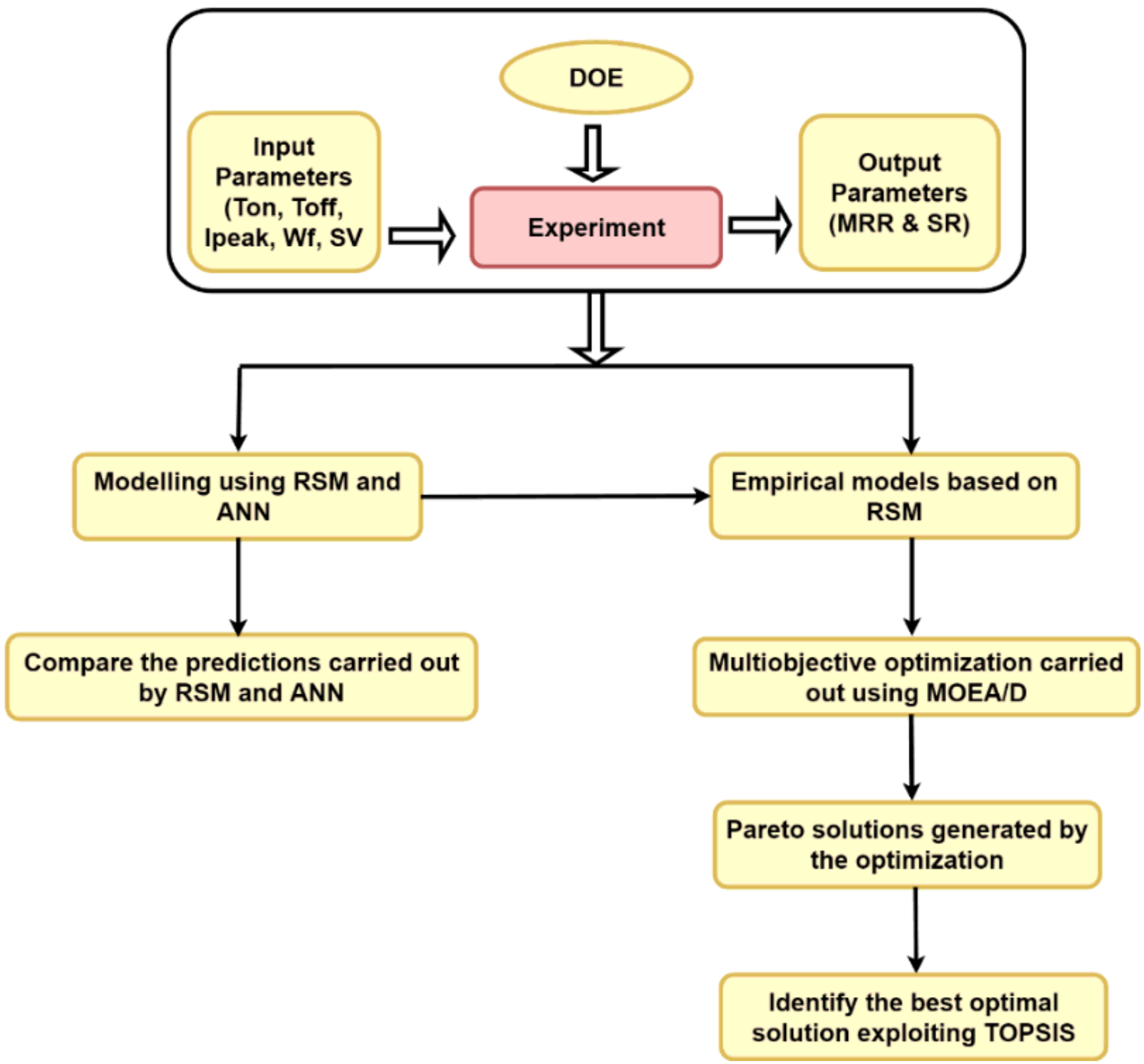

Figure 1

Work-flow of the present study. 


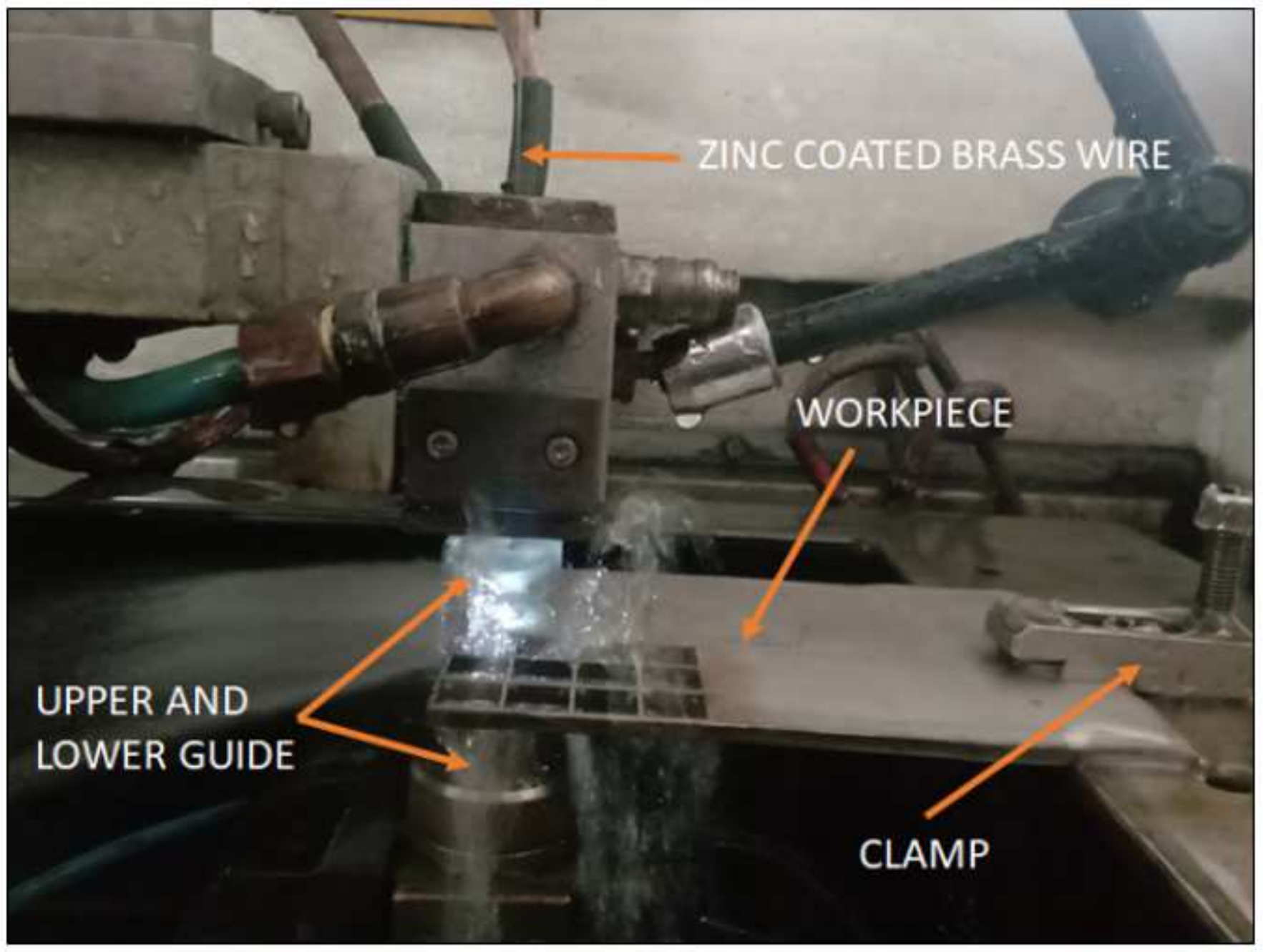

Figure 2

WEDM machining setup. 


\section{Set External Population}

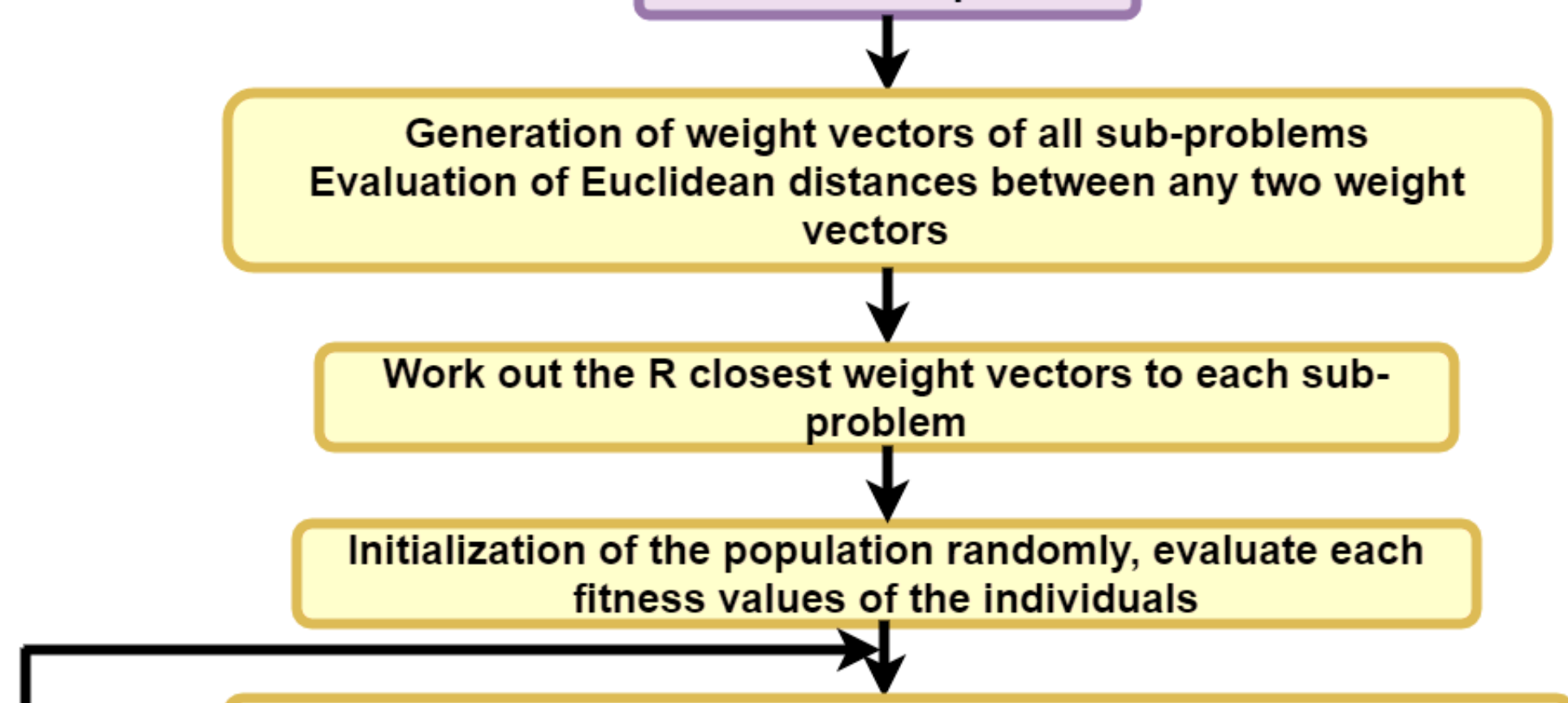

Generate new individual for subproblem using Genetic operator

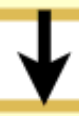

Evaluate new individual exploiting decomposition method and update the solution

Satisfy End Criteria

Figure 3

MOEA/D flow diagram.

Output solution as the optimal results 

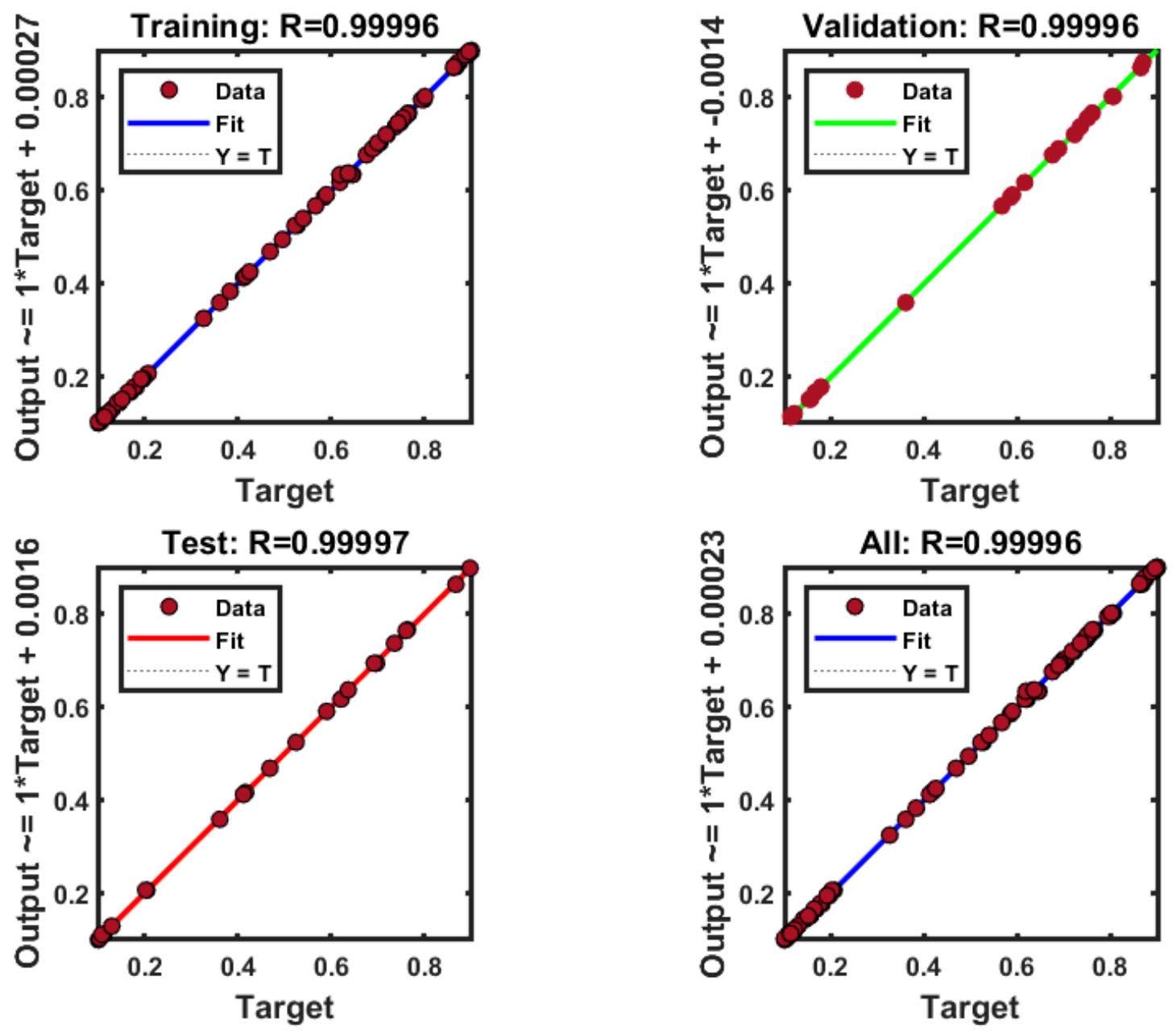

Figure 4

Training, testing, validation and overall scatter plots for 5-9-2 network. 


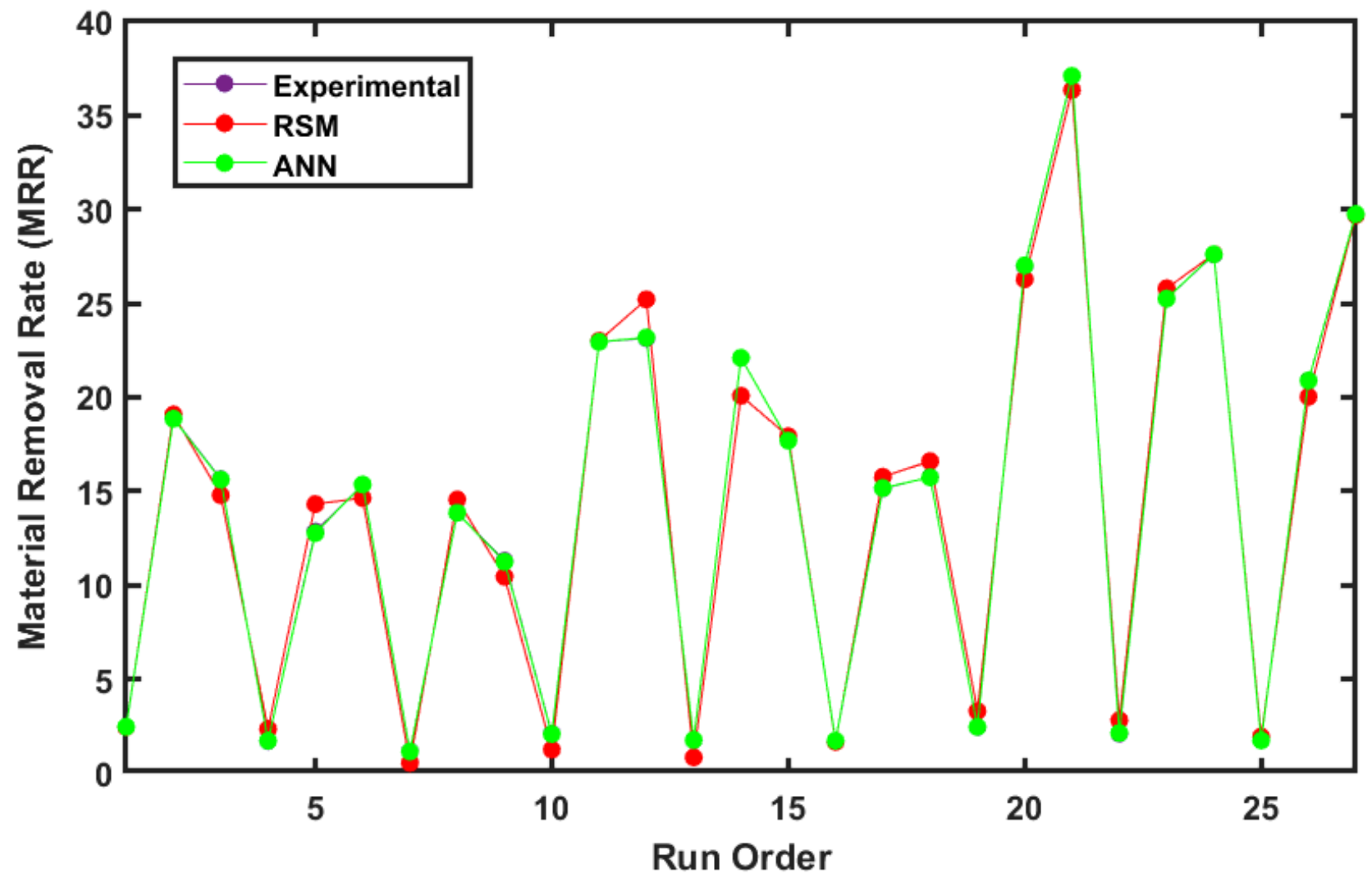

Figure 5

Plots showing comparison between ANN and RSM predictions for MRR.

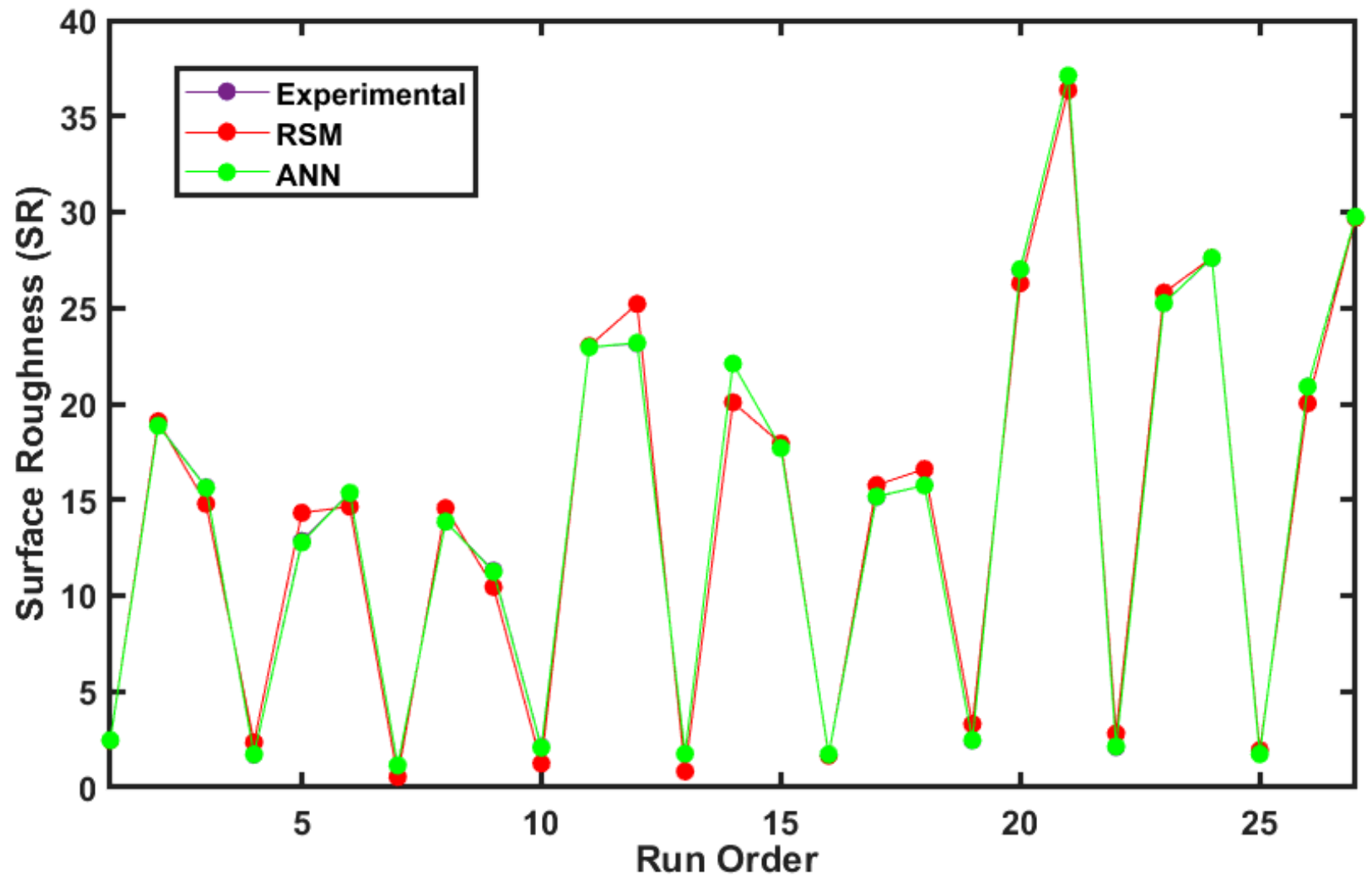


Figure 6

Plots showing a comparison between ANN and RSM predictions for SR.

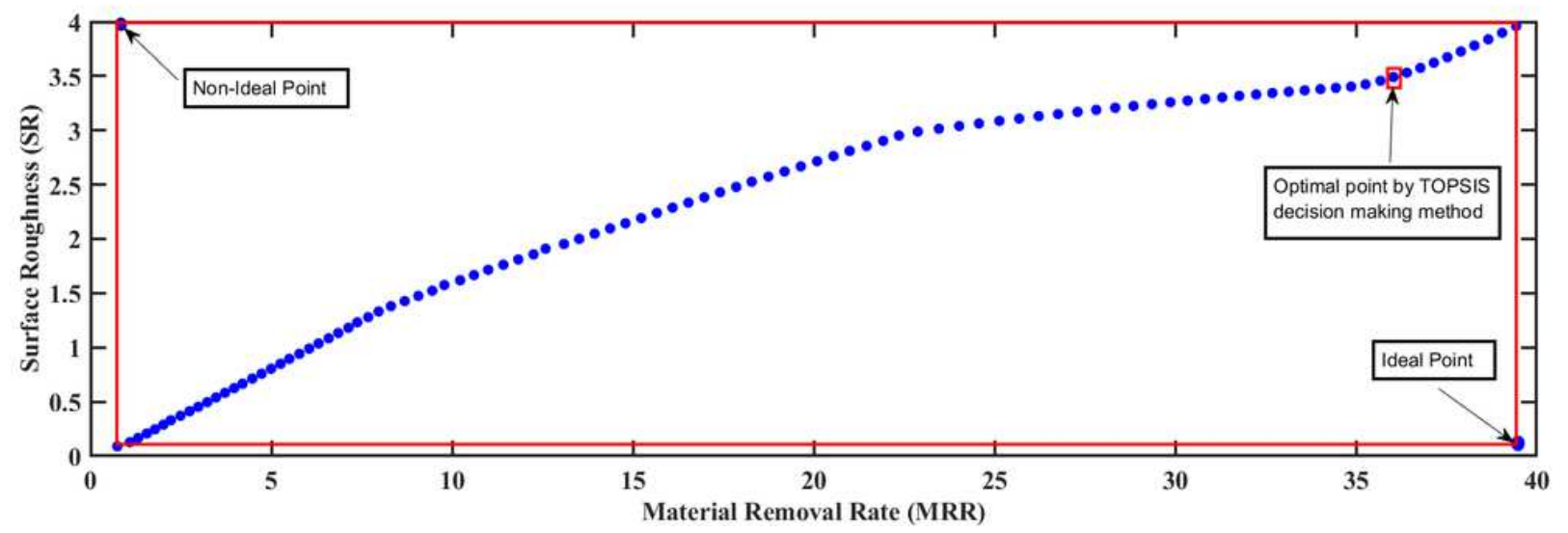

Figure 7

Pareto front with TOPSIS selection. 